\title{
Solar Power Forecasting: A Review
}

\author{
D. K. Chaturvedi \\ Professor, Deptt. of Electrical Engineering \\ Faculty of Engineering, \\ Dayallbagh Educational Institute \\ Agra, India
}

\author{
Isha \\ Research Scholar, Deptt. of Electrical Engineering \\ Faculty of Engineering, \\ Dayalbagh Educational Institute \\ Agra, India
}

\begin{abstract}
The increasing demand for energy is one of the biggest reasons behind the integration of solar energy into the electric grids or networks. To ensure the efficient use of energy PV systems it becomes important to forecast information reliably. The accurate prediction of solar irradiance variation can enhance the quality of service. This integration of solar energy and accurate prediction can help in better planning and distribution of energy.

Here in this paper, a deep review of methods which are used for solar irradiance forecasting is presented. These methods help in selecting the appropriate forecast technique according to the needs or requirements. This paper also presents the metrics that are used for evaluating the performance of a forecast model.
\end{abstract}

\section{Keywords}

Solar forecasting, physical method, statistical method, hybrid method, evaluation metrics.

\section{INTRODUCTION}

World demand for energy is projected to more than double by 2050 and to more than triple by the end of the century. Incremental improvements in existing energy networks will not be adequate to supply this demand in a sustainable way. Finding sufficient supplies of clean energy for the future is one of society's most daunting challenges.

The supply and demand of energy is determining the course of global development in every sphere of human activity. Sufficient supplies of clean energy are intimately linked with global stability, economic prosperity and quality of life. Finding energy sources to satisfy the world's growing demand is one of the society's foremost challenges for the next half century. The importance of this pervasive problem and the perplexing technical difficulty of solving it require a concerted national effort marshalling our most advanced scientific and technological capabilities.

Solar forecasting is a stepping stone to these challenges. Solar power forecasting depends on the factors like knowledge of the sun's path, the atmosphere's condition, the scattering process and the characteristics of a solar energy plant which utilizes the sun's energy to create solar power. Solar photovoltaic systems transform solar energy into electric power. The output power depends on the incoming radiation and on the solar panel characteristics. Photovoltaic power production is increasing nowadays. Forecast information is essential for an efficient use, the management of the electricity grid and for solar energy trading.

Various solar forecasting research activities get motivated due to the factors that accurate solar forecasting techniques improves the quality of the energy delivered to the grid and minimize the additional cost associated with weather dependency.

Solar forecasts on multiple time horizons play an important role in storage management of PV systems, control systems in buildings, hospitals, schools etc., control of solar thermal power plants, as well as for the grids' regulation and power scheduling. It allows grid operators to adapt the load in order to optimize the energy transport, allocate the needed balance energy from other sources if no solar energy is available, plan maintenance activities at the production sites and take necessary measures to protect the production from extreme events.

On the basis of the application and the corresponding time scale required, various forecasting approaches are introduced. For time horizon from several minutes up to a few hours i.e., for very short term time scale, time series models using onsite measurements are adequate. Intra-hour forecasts with a high spatial and temporal resolution may be obtained from ground-based sky imagers. For a temporal range of 30 minutes up to 6 hours satellite images based cloud motion vector forecasts show good performance. Grid integration of PV power mainly requires forecasts up to two days ahead or even beyond. These forecasts are based on numerical weather prediction (NWP) models. Kostylev and Pavlovski [1] gave detailed solar forecast time scales and their corresponding granularities.

For solar forecasting different types of solar power systems need to be distinguished. For solar concentrating systems (concentrating solar thermal or concentrating PV, CPV) the direct normal incident irradiance (DNI) must be forecast. Due to non-linear dependence of concentrating solar thermal efficiency on DNI and the controllability of power generation through thermal energy storage (if available), DNI forecasts are especially important for the management and operation of concentrating solar thermal power plants. Without detailed knowledge of solar thermal processes and controls, it is difficult for 3rd parties (solar forecast providers) to independently forecast power plant output. 


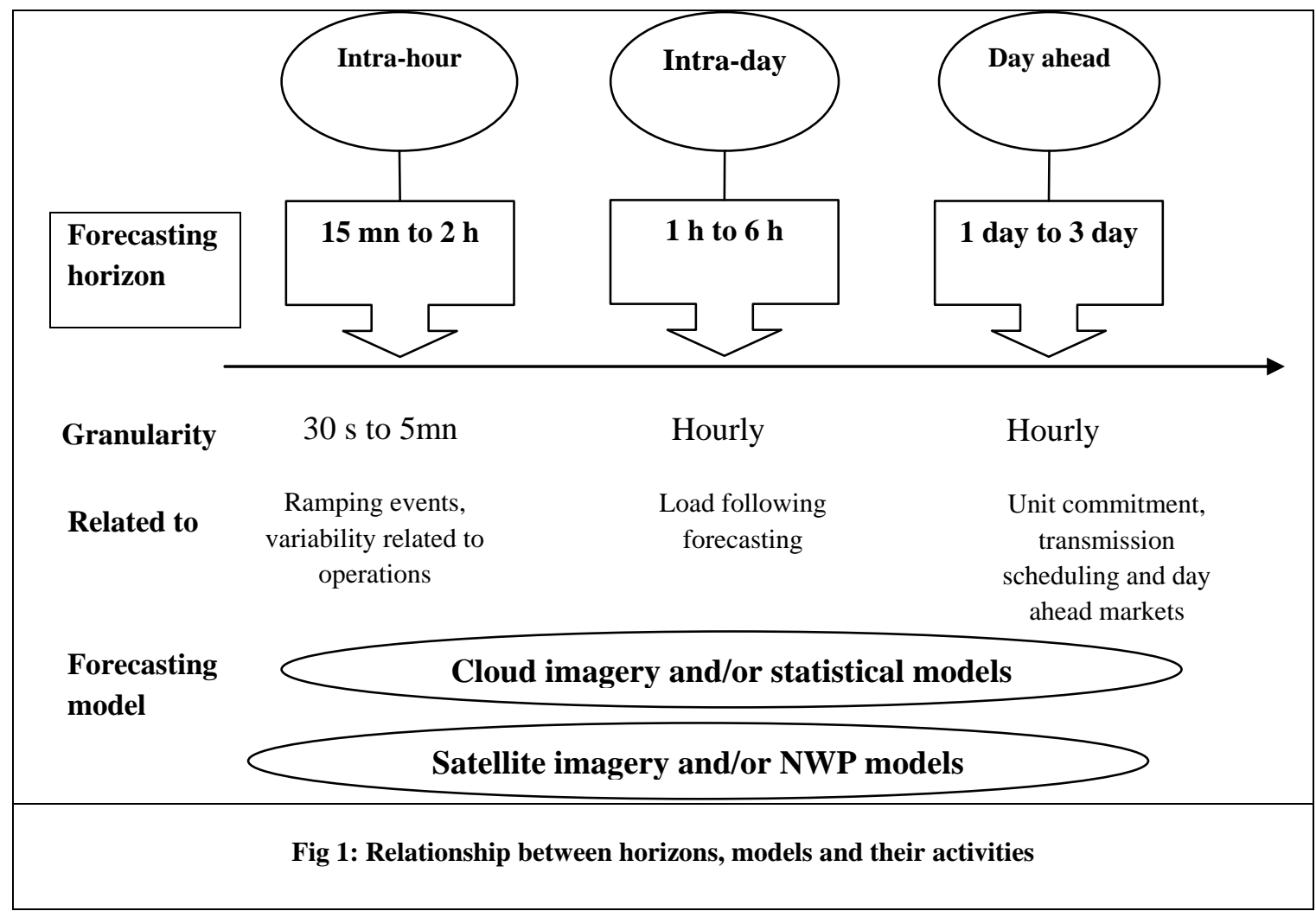

On the other hand, CPV production is highly correlated to DNI. DNI is impacted by phenomena that are very difficult to forecast such as cirrus clouds, wild fires, dust storms, and episodic air pollution events which can reduce DNI by up to 30percent on otherwise cloud-free days. Water vapor, which is also an important determinant of DNI, is typically forecast to a high degree of accuracy through existing NWP. Major improvement in aerosol and satellite remote sensing are required to improve DNI forecasts.

For non-concentrating systems (such as most PV systems), primarily the global irradiance $(\mathrm{GI}=$ diffuse $+\mathrm{DNI})$ on a tilted surface is required which is less sensitive to errors in DNI since a reduction in clear sky DNI usually results in an increase in the diffuse irradiance. Power output of PV systems is primarily a function of GHI. For higher accuracy, forecast of PV panel temperature are needed to account for the (weak) dependence of solar conversion efficiency on PV panel temperature.

\section{SOLAR FORECASTING METHODOLOGIES}

Broadly solar power forecasting methods are classified into three categories: physical methods, statistical methods and hybrid methods.

\subsection{Physical Methods}

The physical method is based on the numerical weather prediction (NWP), cloud observations by satellite or Total Sky Imager (TSI) or atmosphere by using physical data such as temperature, pressure, humidity and cloud cover.

\subsubsection{Cloud Imagery and Satellite Based Models} The satellite and cloud imagery based model is a physical forecasting model that analyzes clouds. The satellite imagery deals with the cloudiness with high spatial resolution. The high spatial resolution satellite has the potential to derive the required information on cloud motion. The cloud motion helps in locating the position of cloud and hence solar irradiance can be forecasted. The parameters which have the most influence on solar irradiance at the surface are cloud covers and cloud optical depth. The processing of satellite and cloud imageries are done in order to characterize clouds and detect their variability and then forecast the GHI up to 6 hours ahead. This model works by determining the cloud structures during earlier recorded time steps. The structure of the clouds and their positions helps in predicting solar irradiance [2].

\subsubsection{Physical Satellite Models}

The basis of physical satellite models for the purpose of solar irradiance forecasting is totally dependent on the interaction between the atmospheric components like gases and aerosols and the solar radiation. These physical interactions are modelled by way of RTMs. Therefore, physical satellite models are said to be improved RTM based clear sky models. This improvement is through the addition of information regarding current atmospheric conditions. The account of atmospheric conditions is through the measurement of local meteorological data. This eliminates the need for solar irradiance data at the surface, however, because these models need to convert digital counts from satellite based radiometers into a corresponding flux densities, accurate and frequent calibration of the instrument is required [3]. Physical satellite models cover four sub models in it.

\section{Gautier-Diak-Masse Model}

One of the earliest physical models was developed by Gautier, Diak and Masse (GDM) in 1980 [4]. In this model clear and cloudy conditions are considered separately. To differentiate a given pixel as clear and cloudy brightness threshold is obtained by selecting a minimum value at every pixel for every hour from the past several days. One shortcoming of the original GDM model was the absence of variations in terrestrial albedo with changing solar zenith angle. Raphael 
and Hay [5, 6] included the T-minimum brightness determination [7] in order to correct for the previous consideration.

In GDM clear sky RTM model the parameters which are used as input are: reflection coefficient for diffuse radiation; these coefficients were calculated using the results from Coulson [8, 9]; the absorption coefficient for slant water vapour path and the solar zenith angle; these absorption coefficients used the expression from Paltridge [10]. Other parameters include the atmospheric albedo as a function of the irradiance received by the satellite. Enhancements and improvements to GDM model includes absorption of ozone and aerosols [11] in addition to multiple reflections by [12].

In GDM cloudy sky RTM model absorption is considered in terms of upwelling and downwelling. This upwelling and downwelling are terms used for absorption above and below the clouds respectively. The parameters used as inputs for cloudy sky RTM are: cloud albedo as a function of the absorption of short wave radiation above and below the clouds, and cloud absorption coefficient estimated on the basis of the satellite's measurement of the visible brightness of the cloud. The relationship between measured visible brightness and absorption is given by Gantier in 1990 [4].

\section{Marullo-Dalu-Viola Model}

This model is the re-evaluation of the GDM model by using the data for the METEOSAT data for the Italian peninsula [13]. This model is similar to GDM model where clear sky and cloudy sky are considered separately. The only difference is in the name clear sky and cloudy sky are termed as standard atmosphere and real atmosphere respectively.

The MDV "standard atmosphere" model is similar to GDM clear sky model. In this, information regarding temperature profile of the atmosphere, water vapour content and a three layer aerosol column are considered [14]. A reflecting nonabsorbing layer which accounts for the presence of aerosols in atmosphere is added in input parameters apart from all the rest used in GDM clear sky model. In MDV model planetary albedo for a standard atmosphere was assumed to be uniform for the region varying only with solar zenith angle. Planetary albedo for a standard atmosphere was approximated though the use of regional clear sky data and assumed to be uniform for the region and varied only with solar zenith angle.

Any significant deviation from the standard atmosphere model was assumed to be a consequence of atmospheric particle loading. The atmospheric loading in the real atmosphere was resolved by a thin reflecting non-absorbing layer assumed to be higher than the particles responsible for scattering in the standard atmosphere.

\section{Moser-Raschke Model}

This model also used METEOSAT images for estimating ground level irradiance [15]. The authors used the RTM developed by Kerschgens [16] which was more complex than the previous models. The only improvements in MR method are addition of parameters for accurately describing the atmospheric state and infrared data so as to estimate the cloud top height.

The input parameters include the solar zenith angle, cloud top height, optical depth of the clouds, terrestrial albedo, boundary layer structure, climatological profiles of temperature, pressure, humidity, ozone concentration and cloud droplet size distribution. One significant result of this model was the demonstration that clouds, rather than aerosols, have a greatest impact on irradiance reaching ground level.

\section{Dedieu-Deschamps-Kerr Model}

This model is different from GDM and MDV model where clear sky and cloudy sky methods were considered separately. DDM model [17] used a single equation valid for both clear and cloudy conditions. For using a single equation clear sky model was combined with the model having only the effects of clouds on solar irradiance.

The input parameters include a sky transmissivity factor, which accounted for Mie and Rayleigh scattering as well as gaseous absorption using the formulae of Lacis and Hansen [18] together with the RTM of Tanre [12], and planetary and terrestrial albedo determined from with the METEOSAT radiometer data. Multiple reflections between the cloud base and the ground were assumed to behave isotropically. It should be noted that as a consequence of uniformity of the aerosol content in both the clear sky and cloudy conditions the model treats an unusually strong concentration of aerosols as a cloud [7].

\subsubsection{Statistical Satellite Models}

These models are defined on the basis of the regression between the pyranometer based solar irradiance at ground level and simultaneous digital counts provided by satellite based instruments. The various parameters in regression equations include solar zenith angle, cloud cover index, atmospheric transmissivity, along with current brightness, minimum brightness and maximum brightness of each pixel. According to [7] the two main difficulties which arise when comparing satellite and ground data are errors associated with the localization of the ground based pyranometer sites on the satellite images and the fundamental difference in the measurement technique. According to some authors $[19,20]$ these problems can be solved by incorporating more pixels in the definition of target areas by enhancing the satellite resolution.

\section{Hay-Hanson model}

One of the simplest statistical satellite models was developed by Hay and Hanson (HH) in 1978 [21]. The model was developed for the Global Atmospheric Research Program's Atlantic Tropical Experiment to generate maps of the shortwave radiation $(0.55-0.75 \mu \mathrm{m})$ reaching the surface of the ocean. The $\mathrm{HH}$ model is based of a statistical linear regression of the clearness index and atmospheric absorptivity:

$$
\mathbf{K}_{\mathbf{t}}=\mathbf{a}-\mathbf{b} \boldsymbol{\alpha}_{\mathbf{a}}
$$

Hay and Hanson [21] originally determined regression coefficients $\mathrm{a}$ and $\mathrm{b}$ as

$$
a \cong 0.79 \quad b \cong 0.71
$$

These values were later re-evaluated by Raphael and Hay [3] to be

$$
a \cong 0.788 \quad b \cong 1.078
$$

which gives a better agreement with their dataset.

It has been pointed out in [7] that this relationship fails under unusually high surface albedo which results from a snow- or ice-covered surface. In addition, despite what has been mentioned about statistical methods, this approach requires 
the calibration of reported digital satellite counts $\mathrm{i}$ order to determine visible radiance.

\section{Tarpley \& Justus-Paris-Tarpley Models}

Tarpley used a set of coincident satellite and ground pyranometer data sets taken by the National Environmental Satellite Data and Informations Services (NESDIS) and the Great Planes Agricultural Council over the central U.S. in late 1970s [22]. This study made use of statistical regressions against measurements from GOES VISSR. Three separate cases were considered based on the value of the cloud index defined by Tarpley as,

$$
\boldsymbol{n}=\frac{0.5 N_{2}+N_{3}}{N}
$$

where $\mathrm{N}$ is the total number of pixels included in the target area, and $\mathrm{N}_{2}$ and $\mathrm{N}_{3}$ are the number of pixels in partly cloudy and cloudy conditions respectively. The Tarpley regression model was defined as,

$$
I=\left\{\begin{array}{lr}
a+b \cos (\theta)+c K_{t}+d n+e\left(\frac{B_{m}}{B_{0}}\right)^{2} & \text { if } n \leq 0.4 \\
a+b \cos (\theta)+c n\left(\frac{B_{c l d}}{B_{n}}\right)^{2} & \text { if } 0.4<n<1 \\
a+b \cos (\theta)+c\left(\frac{B_{c l d}}{B_{n}}\right) & \text { if } n=1
\end{array}\right.
$$

where $B_{m}$ is the mean target brightens, defined as the mean brightness of a $7 \times 6$ pixel array; $\mathrm{B}_{\text {cld }}$ is the mean cloud brightness, estimated through an average of the brightness values of all the pixels in the target area brighter than a specified threshold; and $\mathrm{Bn}=\mathrm{B} 0\left(\theta \mathrm{z}=45^{\circ}, \phi \mathrm{s}=105^{\circ}\right)$ is the normalized clear brightness which is a special case of the clear brightness $\mathrm{B}_{0}$ which is obtained from the following regression,

$$
\begin{gathered}
B_{0}= \\
a+b \cos \left(\theta_{z}\right)+c \sin \left(\theta_{z}\right) \cos \left(\phi_{s}\right)+d \sin \left(\theta_{z}\right) \cos ^{2}\left(\phi_{s}\right)
\end{gathered}
$$

Raphael and Hay [23] also estimated their own regression coeffcients for this model which are different from Tarpley's treatment.

This model was later refined by Jutus, Paris and Tarpley (JPT) [24] for part of the Agriculture and Resources Inventory Surveys through Aerospace Remote Sensing (AgRISTARS) program. This new model replaced the three equations of Tarpley's model with the following single equation,

$$
\begin{gathered}
I=I_{0}\left(\frac{r_{0}}{r}\right)^{2} \cos \left(\theta_{z}\right)\left[a+b \cos \left(\theta_{z}\right)+c \cos ^{2}\left(\theta_{z}\right)\right]+d\left(B_{m}^{2}-\right. \\
\left.B_{0}^{2}\right)
\end{gathered}
$$

where $\mathrm{B}_{\mathrm{m}}$ is again the mean observed target brightness and $\mathrm{B}_{0}$ is defined by the following relationship,

$$
\left\{\begin{array}{cl}
B_{0}= & \\
B_{0}^{\prime} & \text { if } B_{m} \geq B_{\text {max }} \\
\omega_{1} B+0^{\prime}+\left(1-\omega_{1}\right) B_{m} & \text { if } B_{0}^{\prime}<B_{m}<B_{\text {max }} \\
B_{m} & \text { if } B_{0}^{\prime}-2<B_{m} \leq B_{0}^{\prime} \\
\omega_{2} B+0^{\prime}+\left(1-\omega_{1}\right) B_{m} & \text { if } B_{\text {min }} \leq B_{m}<B_{0}^{\prime}-2 \\
B_{0}^{\prime} & \text { if } B_{m}<B_{\text {min }}
\end{array}\right.
$$

As before, the authors in [24] assumed that the brightness for clear sky conditions $B_{0}^{\prime}$ and the measured target mean brightness $B_{m}$ were known. The weights $w_{l}$ and $w_{2}$ are values between 0 and 1 which were empirically determined. Each of the cases above approximates various conditions of the atmosphere. The first and fifth cases correspond to the likely presence of clouds and the insufficient scene illumination for radiation forecasts respectively; each of these cases leaves the clear brightness unaltered. The second case allows for seasonal variation in the clear brightness due to snow- or icecover. The third case is to account for clearer than normal days while the fourth case allows for the removal of erroneous effects from the satellite image on $\mathrm{B}_{0}$ [7].

\section{Cano-HELIOSAT Model}

Cano developed a model for the French HELIOSAT project in 1982 which used visible band METEOSAT data [25]. The Cano-HELIOSAT model proposes a simple linear relationship between the clearness index $K_{t}$ and the cloud index $n_{t}$ at the same point in time and space. This is accomplished by considering local values of $K_{t}$ and $n_{t}$ at each pixel as,

$$
K_{t}(i, j)=A(i, j) n_{t}(i, j)+B(i, j)
$$

where A and B are matrices of regression coefficients [26]. The cloud cover index was defined as,

$$
n_{t}(i, j)=\frac{\rho_{t}(i, j)-\rho_{0}(i, j)}{\rho_{c}-\rho(i, j)}
$$

where $\rho_{t}$ is the measured ground albedo, $\rho_{0}$ is the reference ground albedo and $\rho_{c}$ is the average albedo of the top of the clouds. The reference ground albedo was calculated using Bourges model [27] and a recursive procedure which minimized the variance of the errors of the clear sky model.

Refinements to the Cano-HELIOSAT model include use of the ESRA clear sky model to correct the estimation of the terrestrial and atmospheric albedos by Rigollier et al. [28]. These corrections were subsequently used to derive the following relationship between the cloud index $n_{t}$ and a clear sky index $k_{t}$,

$$
\begin{gathered}
k_{t}= \\
\left\{\begin{array}{lr}
1.2 & \text { if } n_{t}<-0.2 \\
1-n_{t} & \text { if }-0.2 \leq n_{t}<0.8 \\
2.0667-3.6667 n_{t}+1.6667 n_{t}^{2} & \text { if } 0.8 \leq n_{t}<1.1 \\
0.05 & \text { if } n \geq 1
\end{array}\right.
\end{gathered}
$$

More recent developments of the Cano-HELIOSAT model include consideration of the three dimensional structure of cloud in the determination of the cloud index [29], modification of the previous $k_{t}-n_{t}$ relationship to include moments of the cloud index distribution [30], corrections for non-Lambertian reflectivity and the backscattering of clouds [31] and integration of the SOLIS-RTM platform [32]. 


\section{Perez Operational Model}

One of the most widely used statistical satellite models is the operational model of Perez [33]. The Perez model uses a modified version of Kasten's clear sky model which defines a Link turbidity coefficient independent of air mass [34]. The model also allows for the modification of the algorithm based on real time measurements of snow- or ice-cover as well as the correction of sun satellite angle effects for each pixel [35].

The model relates hourly global irradiance $\mathrm{I}_{\mathrm{t}}$ and cloud index $n_{t}$ through a simple regression:

$$
I_{t}=I_{c l r,}{ }_{t} f\left(n_{t}\right)\left[a I_{c l r, t}+b\right](10)
$$

where $f\left(n_{t}\right)$ is a fifth order polynomial of the cloud index given by,

$$
f\left(n_{t}\right)=c_{5} n_{t}^{5}+c_{4} n_{t}^{4}+c_{3} n_{t}^{3}+c_{2} n_{t}^{2}+c_{1} n_{t}+c_{0}
$$

Values of the coefficients as calculated by Perez in are given in [35]. This model was also modified by Perez and Ineichen to forecast DNI from GHI forecasts provided by the operational model as well as corrections for locations presenting complex arid terrain [36].

\subsubsection{Total Sky Imagers}

The satellite and cloud imagery based model is a physical forecasting model that analyses clouds. The satellite imagery deals with the cloudiness with high spatial resolution. The high spatial resolution satellite has the potential to derive the required information on cloud motion. The cloud motion helps in locating the position of cloud and hence solar irradiance can be forecasted. The parameters which have the most influence on solar irradiance at the surface are cloud covers and cloud optical depth. The processing of satellite and cloud imageries are done in order to characterize clouds and detect their variability and then forecast the GHI up to 6 hours ahead. This model works by determining the cloud structures during earlier recorded time steps. The structure of the clouds and their positions helps in predicting solar irradiance [2][37] Successfully used Total Sky Imager (TSI) in predicting very short and short-term forecasting.

Both NWPs and satellite imaging techniques lack the spatial and temporal resolution to provide information regarding high frequency fluctuations of solar irradiance. An alternative is provided through ground based imaging of local meteorological conditions. One instrument which has seen increased application lately is the Total Sky Imager (TSI) manufactured by Yankee Environmental Systems [38].

Typically the methodology for ground based images is similar to satellite based techniques. Projections of observed solar radiation conditions based on immediate measured history while the position and impact of clouds is deduced from their motion. In the case of TSIs the CCD image is digitally processed in order to detect locations of the sky covered by clouds. The cloud image is then propagated forward in time resulting in a forecast. TSI images are useful for prediction of GHI on time horizons up to 15 minutes.

TSI can be used to forecast both the Direct Normal Irradiance (DNI) [39-41] and GHI [37] [42-43]. In some researches researchers also use commercially available TSI such as TSI800 manufactured by Yankee Environmental Systems [44], while other researchers develop their own TSIs [45].
Sky images are taken sequentially in time; cloud information can be derived from the images through image processing. Template matching algorithms [46-48] are used for computing the motion vectors describing the movement of clouds based on consecutive images. Forecast can thus be obtained through persisting the motion vectors or more sophistically, by solving the advection-diffusion equation [49]. In recent reports it has been found that forecasting based on deterministic ray tracing method produces forecasts that are worse than persistence, at $5,10,15 \mathrm{~min}$ forecast horizon [50]. In terms of normalized Root Mean Square Error (nRMSE), forecast error using TSI varies from 18 to $24 \%$ for forecast horizons ranging from $30 \mathrm{~s}$ to 15 min [45]. Nevertheless, due to its physical-based nature and its potential, TSI-based methods are quickly adopted by many other groups in the past two years not only for irradiance forecasting [51] but also used for general atmospheric research [52].

For the purpose of determining and forecasting of local solar radiation conditions geostationary satellite images obtained from the METEOSAT satellite have been used. The basis of this method relies upon the determination of the cloud structures during the previous recorded time steps. For the forecast, cloud motion vector algorithms ([53]; [54]) can be used to obtain the cloud conditions at the next time step ([55], [56]), mapping is then performed on the forecast images to obtain the future irradiance. Extrapolation of their motion leads to a forecast of cloud positions and, as a consequence, to the local radiation situation. This method has the advantage of producing a spatial analysis of an area within certain resolution capabilities. The improvement over the persistent method is small, according to the authors.

[54], [37] used satellite imagery and ground-based sky imager respectively for solar forecasting.

It should be noted that while these TSI based provide local meteorological information enabling intra-hour forecasts, their time horizon is restricted to approximately 30 minutes do to their limited range of view. One possible approach to extend the time horizon of ground based measurements is to distribute an array of imagers so that more information regarding local cloud fields is obtained. However, the relative cost associated with the TSI $(\sim 2,000)$ and the dynamic nature of local cloud fields which may limit the correlation of successive images poses difficulties for current ground based imaging methodologies. In addition to an upper bound on the time horizon of the TSI, a lower band is also imposed. The lower bound is a result of circum-solar scattering of light as well as limitations introduced by the shadow-band which currently renders time horizons shorter than 2 minutes inaccessible [37, 57].

\subsubsection{Wireless Sensor Network Systems}

Satellite and NWP models typically possess time horizons on the order of 30 minutes while stochastic and AI methods have not been widely applied to time horizons less than 15 minutes. TSIs are limited by the circum-solar scattering of light and the shadow-band to time horizons no longer than 3 minutes [37, 57]. Semiconductor point sensors are capable of very high sampling frequencies but fail to correctly characterize the distributed nature of an operational scale PV plant [58]. An alternative has been suggested by Coimbra and coworkers at the University of California, Merced [156]. A 1MW PV array was outfitted with with 40 TelosB nodes equipped with low cost solar irradiance sensors. The authors in [59] proposed a forecasting algorithm which utilized multiple readings from the spatially distributed network of sensors to compute future 
values of the distributed power output. The forecasting approach utilized spatial cross-correlations between sensor nodes which provided forecasts in the range of 20-50 seconds. Calculated velocities agreed with TSI calculated cloud velocity field over $70 \%$ of the time [59]. This work demonstrates the potential of wireless sensor networks as low cost and highly accurate approaches for intra-minute solar forecasting.

\subsubsection{Numerical Weather Prediction Models}

The numerical weather predictions purely rely upon the atmospheric physics. It is the study of how current observations of the weather are used and then processed to predict the future states of the weather. This is done with the help of super computers. A process called assimilation is done so as to process the current weather states and produce outputs of temperature, wind, irradiance and other hundreds of meteorological elements. The NWP is good for one day to multi-days ahead horizons. Thus, it is a useful tool for different variety of applications, such as the scheduling of solar power plants. NWP is also helpful in predicting the transient variations in clouds, which are considered the major obstacles for solar irradiance at the ground. After the assimilation of current observations, the NWP forecasts the future conditions and then the error is corrected based on the previous performance by a statistical post processing.

NWP processes as follows: In the first step the initial states of atmosphere are collected with the help of different sources such as satellites and ground observations. The key source of the NWP error is "data-assimilation", which is a complex process. This occurs because sources measure different quantities of current states over different volumes of a space and that creates an error in the measurement. In the second step, the main important equations of atmosphere, such as dynamics equations, Newton's second law for fluids flow, thermodynamics equations, and radiative transfer equations are integrated and solved [60]. In solar engineering, the physical laws of motion and thermodynamics are rarely scrutinized in detail. As NWP models output hundreds of parameters in each run, irradiance is but one of them, researchers simply run NWP models [61-63] and study the outputs. As most of the NWP models are not adapted specifically for irradiance forecasting purposes, biased forecasts commonly result. Finally, the statistical postprocessing step where the output of the NWP is manipulated using a trial and error after simulation, in order to compare the outputs with observations and find the statistical relation, and hence correct the error. Statistical post-processing such as the application of model output statistics and Kalman filtering are thus used to obtain useful results [64-65].

There are two models in which NWP models can be classified: Global models and Regional models. In global models, global or worldwide simulation of the behaviour of the atmosphere is carried out, where as in regional (mesoscale) models it is done on a continent or a country scale [66]. Well known NWP models include Global Forecast System (GFS), North American Mesoscale (NAM) model and Weather Research and Forecasting (WRF) model. The difference amongst the three occurs in terms of spatial resolution, input parameters and most importantly, the under lying physical models. It is therefore important to choose the forecasting domain, improve data collection and select an NWP system that uses suitable physical models when one attempts to forecast irradiance.
In their current development, NWPs does not predict the exact position and extent of cloud fields. Their relatively coarse spatial resolution (typically on the order of $1-20 \mathrm{~km}$ ) renders NWP models unable to resolve the micro-scale physics that are associated with cloud formation. Therefore, NWP based solar forecast shows cloud prediction in accuracy which is considered as one of the largest sources of errors in NWP. The benefits given by NWP are, it works for long time horizons (15 to 240 hours). With the help of regional and global modelling of atmospheric physics it is possible to obtain information about the propagation of large scale weather patterns. As compared to satellite based methods NWPs shows more accurate results of forecast for time horizons exceeding 4 hours [67-68]. Accordingly, NWPs provide the most attractive option for medium to long term atmospheric forecasting.

For time horizons exceeding 6 hours, up to several days ahead, it is advisable to use NWP for accurate results. NWP models predict GHI using columnar (ID) radiative transfer models. [69] Showed that the MM5 mesoscale model can predict GHI in clear skies without mean bias error (MBE). However, the bias was highly dependent on cloud conditions and becomes strong in overcast conditions.

Many scientists [68], [70-72] evaluated different NWP based GHI forecast at different locations. For all the locations various RMSE percentage are calculated.

NWP and satellite forecasts are inadequate for achieving high temporal and spatial resolution for intra hour forecasts. This gap can be filled by ground observation using a sky imager and delivers a sub-kilometre view of cloud shadows over a large scale PV power plant or an urban distribution feeder.

Model Output Statistics (MOS) is a post-processing technique which is used for interpreting numerical model output and producing site-specific forecasts. A statistical approach is used by MOS for relating observed weather elements with appropriate variables (predictors). These predictors can be NWP model forecast, prior observations, or geo-climatic data.

Consistent error patterns allow for MOS to be used to produce a bias reduction function for future forecasts. [73] Used MOS and calculated $24.5 \%$ RMSE for averaged daily forecasts. Similarly other authors [68], [65] used MOS correction function for eliminating bias and reduced RMSE.

\subsubsection{Global Forecast System (GFS)}

One of the most well-known global NWP models is the Global Forecast System (GFS). The GFS model is run by NOAA (National Oceanic and Atmospheric Administration) every six hours and produces forecasts up to 384 hours (16 days) in advance on a $28 \mathrm{~km} \times 28 \mathrm{~km}$ grid for the global domain [74]. The GFS loop time steps are 6 hours out to 180 hours (7.5 days), then change to 12-hour time steps out to 384 hours (16 days). In addition to the $28 \mathrm{~km} \mathrm{x} 28 \mathrm{~km}$ horizontal discretization, the GFS models 64 vertical layers of the atmosphere. The RTM of the GFS accepts as inputs: predicted values of a fully three dimensional aerosol concentration field, predicted values of a two dimensional (horizontal) $\mathrm{H}_{2} \mathrm{O}, \mathrm{O}_{2}$ and $\mathrm{O}_{3}$ concentration field as well as a constant two dimensional (horizontal) $\mathrm{CO}_{2}$ field. The GFS model also calculates wavelength specific attenuation of both upwelling and downwelling diffuse irradiances through a sophisticated scattering/absorbing scheme [75]. It should be noted that the radiant flux attenuation is dependent on $\mathrm{H}_{2} \mathrm{O}$ phase, temperature and particle size which makes the GFS sensitive to temperature errors. 


\section{The European Centre for Medium-Range Weather Forecasts (ECMWF)}

The ECMWF provides weather forecasts up to 15 days ahead, including solar surface irradiance and different cloud parameters as model output. ECMWF forecasts have shown their high quality as a basis for both wind and solar power forecasts. These forecasts are described here as an example of global NWP model forecasts. The evaluations of ECMWFbased irradiance in Lorenz et al. $[61,76,77]$ are based on the T799 version with a spatial resolution of $25 \mathrm{~km} \times 25 \mathrm{~km}$. The current version T1279 was implemented in January 2010 and shows a horizontal resolution of $16 \mathrm{~km}$ x $16 \mathrm{~km}$. Ninety-one hybrid vertical levels resolve the atmosphere up to $0.01 \mathrm{hPa}$ corresponding to approximately $80 \mathrm{~km}$. The temporal resolution of the forecasts is $3 \mathrm{~h}$ for the first 3 forecast days that are most relevant for PV power prediction. Temporally, ECMWF forecasts have a time-step size of $3 \mathrm{hr}$. and are published twice daily up to 10 days in advance.

\subsubsection{Regional NWP Model}

Unlike global NWP models, regional NWP model only a a sub-domain of the global space. Regional models in the U.S. include the Rapid Update Cycle (RUC), RAPid refresh (RAP), North American Mesoscale (NAM) model, High Resolution Rapid Refresh (HRRR) and the Weather Research and Forecasting (WRF) model [155].

\section{Rapid Update Cycle (RUC)/ RAPid refresh (RAP) Models}

The RUC was a NOAA/NCEP (National Centers for Environmental Prediction) operational NWP model until May, 2012. RUC produced hourly updated $13 \mathrm{~km} \mathrm{x} 13 \mathrm{~km}$ horizontally resolved forecasts with 50 atmospheric layers out to a time horizon of 18 hours. The RUC loop time steps are 1 hour from time of analysis out to 18 hours. The RUC possessed a wavelength independent model for the absorption/scattering of radiation by water vapour only. Other atmospheric gasses and aerosols were neglected. The RUC also assumed Rayleigh scattering which failed to capture the inversely proportional relationship between intensity of scattering and wavelength of radiation. In addition, only down welling irradiances were attenuated which sometimes lead to the underestimation of diff use irradiance due to backscattering [78].

As of May 1, 2012 the RUC was replaced with the Rapid Refresh (RAP) model as the next-generation version of the NCEP hourly cycle system. The RAP model possess the same spatial and atmospheric resolution $(12 \mathrm{~km} \times 12 \mathrm{~km}, 50$ layers) but it based on a new rapid update configuration of the WRF model. As a result, the RAP benefited from the ongoing community improvements to the WRF. The domain of the RAP is also significantly larger than the previous RUC and was expanded from the Continental United States (CONUS) region to include Alaska as well.

\section{North American Mesoscaale (NAM) Model}

The North American Mesoscale (NAM) model is the NCEP's primary mesoscale environmental modelling tool. NAM produces $12 \mathrm{~km} \mathrm{x} 12 \mathrm{~km}$ horizontally resolved forecasts with 60 atmospheric layers out to a time horizon of 96 hours over North America and is updated four times daily. The NAM model loop time steps are 6 hours from the time of analysis out to 84 hours ( 3.5 days). The NAM model used predicted water vapor concentrations, seasonally varying but zonally constant $\mathrm{O}_{3}$ concentrations and constant $\mathrm{CO}_{2}$ concentrations. Aerosols are not explicitly considered except for a top of the atmoshpere adjustment, which is not particularly troublesome with the exception of regions with high levels of time varying aerosol concentrations. Wavelength specific attenuation of both upwelling and downwelling fluxes is accounted for.

\section{High Resolution Rapid Refresh (HRRR) Model}

The High Resolution Rapid Refresh (HRRR) model is an NOAA operated, experimental, hourly updated, $3 \mathrm{~km} \times 3 \mathrm{~km}$ resolution atmospheric model. The HRRR was previously only nested over the eastern $2 / 3$ of the continental United States, however as of June 2009 coverage was expanded to the CONUS region similar to the former RUC. The RHHH models uses the $13 \mathrm{~km}$ resolution RUC/RAP for its initial conditions and is updated hourly. Benefits of the HRRR include the increased resolution and frequent updates which allow for shorter timescale predictions [155].

\section{Weather Research and Forecasting (WRF) Model}

Many of the NWPs discussed are based on a version of the WRF which was created thought a partnership between NOAA and the National Center for Atmospheric Research (NCAR) in 2004. The WRF has, since its introduction, seen increased applicability in both research and operational communities. WRF software is supported ongoing efforts including workshops and on-line documentation. One of the main goals of the WRF model is to advance mesoscale atmospheric prediction by promoting closer ties between research and operational forecasting communities. The WRF is flexible by design and intended for a wide variety of forecasting applications with a priority on spatial resolutions ranging from 1 to $10 \mathrm{~km}$ [155].

\subsection{Statistical Methods}

Forecasting methods based on historical data of solar irradiance are categorized into two categories: statistical and learning methods. Seasonality analysis, Box-Jenkins or Auto Regressive Integrated Moving Average (ARIMA), Multiple Regressions and Exponential Smoothing are examples of statistical methods, whilst AI paradigms include fuzzy inference systems, genetic algorithm, neural networks, machine learning, etc.l

\subsubsection{Time Series Models}

As said earlier time series models gives the result based on the historical data. Time series can be defined as a sequence of observations measured over time, such as the hourly, daily or weekly. Since the observation could be random it is also known as stochastic process. A time series technique mainly focuses at the patterns of the data. These patterns should be identifiable and predictable for the time-series based forecast. 
Table 1 Comparison of various NWP models

\begin{tabular}{|c|c|c|c|c|c|c|}
\cline { 2 - 7 } \multicolumn{1}{c|}{} & Model & Resolution & $\begin{array}{c}\text { No. of } \\
\text { layers }\end{array}$ & $\begin{array}{c}\text { Time } \\
\text { Horizon }\end{array}$ & Time Step & Agency \\
\hline \multirow{2}{*}{$\begin{array}{c}\text { Global } \\
\text { Models }\end{array}$} & GFS & $28 \mathrm{~km}$ & 64 & $\begin{array}{c}180 \mathrm{hr}, 384 \\
\mathrm{hr}\end{array}$ & $6 \mathrm{hr}, 12 \mathrm{hr}$ & NOAA \\
\cline { 2 - 7 } & ECMWF & $25 \mathrm{~km}$ & 91 & $360 \mathrm{hr}$ & $3 \mathrm{hr}$ & - \\
\cline { 2 - 7 } & RUC/RAP & $13 \mathrm{~km}$ & 50 & $18 \mathrm{hr}$ & $1 \mathrm{hr}$ & NOAA/NCEP \\
\cline { 2 - 7 } $\begin{array}{c}\text { Regional } \\
\text { Models }\end{array}$ & NAM & $12 \mathrm{~km}$ & 60 & $96 \mathrm{hr}$ & $6 \mathrm{hr}$ & NCEP \\
\cline { 2 - 7 } & HRR & $3 \mathrm{~km}$ & 50 & $15 \mathrm{hr}$ & $15 \mathrm{~min}$ & NOAA \\
\hline
\end{tabular}

\subsubsection{Linear Stationary Models}

Observational series that describe a changing physical phenomenon with time can be classified into two main categories; stationary and non-stationary. If the sequence of weights in Equation (12) below is finite, or infinite and convergent, the linear filter is said to be stable and the process $z_{t}$ (stochastic process) to be stationary [155]. Stationary time series are static with respect to their general shape. The fluctuations may appear ordered or completely random, nonetheless the character of the series is, on the whole, the same in different segments. In this case, the parameter $\mu$ may be interpreted as the average value about which the series fluctuates. Stationary time series find applications in many areas of the physical sciences, for instance, observational time

series and series involving deviations from a trend are often stationary [79]. In fact, the stochastic portion a solar radiation data set is often framed as a stationary process [80].

$$
G(q)=\sum_{k=0}^{\infty} g_{k} \widehat{q}^{k}=1+g_{1} \widehat{q}+g_{2} \widehat{q}^{2}
$$

Where $q$ is the forward shift or advance operator and $G(q)$ is the transfer function of the filter.

\section{Auto-Regressive (AR) Models}

The so-called auto-regressive models get their name from the fact that the current value of the process can be expressed as a finite, linear combination of the previous values of the process and a single shock $\omega_{t}$. Thus, the process is said to be regressed on the previous values. If

we define the stochastic portion of the time series $\tilde{z}_{t}, \tilde{z}_{t-1}, \tilde{z}_{t-2}, \ldots \ldots$ as deviations from the mean value $\mu$ as

$$
\tilde{z}_{t}=z_{t}-\mu
$$

then the Auto-Regressive process of order $m$ can be written as

$$
\begin{gathered}
\omega_{t}=\tilde{z}_{t}+\phi_{1} \tilde{z}_{t-1}+\phi_{2} \tilde{z}_{t-2}+\cdots+ \\
\phi_{m} \tilde{z}_{t-m}(14)
\end{gathered}
$$

We can simplify the previous expression by defining the Auto-Regressive operator of order $m, A R(m)$, as

$$
\Phi_{m}(\boldsymbol{q})=\sum_{k=0}^{m} \phi_{k} \widehat{\boldsymbol{q}}^{k}=\mathbf{1}+\phi_{1} \widehat{\boldsymbol{q}}+\phi_{2} \widehat{\boldsymbol{q}}^{2}+\cdots+\phi_{m} \widehat{\boldsymbol{q}}^{\boldsymbol{m}}
$$

then the $A R(m)$ model may be written conveniently as

$$
\Phi_{m}(q) \tilde{\mathbf{z}}_{t}=\omega_{t}
$$

where it is clear that the process is regressed on the previous values of $\tilde{z}$. In order to implement this model one must determine the $m+2$ unknown parameters $\phi_{1}, \phi_{2}, \ldots \phi_{m}, \mu$ and $\sigma_{\omega}^{2}$. It is illustrative to note that Equation (16) implies

$$
\tilde{z}_{t}=\Phi_{m}^{-1}(q) \omega_{t}
$$

Therefore, it is helpful to think of the $\operatorname{AR}(m)$ process as the output of a linear filter with transfer function $\Phi_{m}^{-1}(q)$ and white noise $\omega_{t}$ as the input.

In order for the $\mathrm{AR}(m)$ process to be stationary a set of conditions must be satisfied. In [81] the authors point out that the general $\mathrm{AR}(m)$ process has the inverse transfer function

$$
\Phi_{m}(\boldsymbol{q})=\left(\mathbf{1}-\Gamma_{\mathbf{1}} \widehat{\boldsymbol{q}}\right)\left(\mathbf{1}-\Gamma_{\mathbf{2}} \widehat{\boldsymbol{q}}\right) \ldots\left(\mathbf{1}-\Gamma_{\boldsymbol{m}} \widehat{\boldsymbol{q}}\right)(18)
$$

which allows expansion of the process in partial fractions,

$$
\tilde{\mathbf{z}}_{t}=\Phi_{m}^{-1}(q) \omega_{t}=\sum_{k=1}^{m} \frac{k_{i}}{\left(1-\Gamma_{i} \widehat{q}\right)} \omega_{t}(19)
$$

where it is clear that if $\Phi_{m}^{-1}(q)$ is to be a convergent series for $|\hat{q}| \leq 1$, then we must have $|\Gamma|<1$, where $k=1,2,3, \ldots m$. This is equivalent to saying that the roots of the equation $\Phi_{m}(q)=0$ must lie outside the unit circle. For a discussion of stationary conditions of $\mathrm{AR}(m)$ processes see $[79,81,82]$.

\section{Moving Average (MA) Models}

While the AR techniques model the stochastic portion of the time series $\tilde{z}_{t}$ as a weighted sum of previous values $\tilde{z}_{t-1}, \tilde{z}_{t-2}, \ldots \tilde{z}_{t-m}$, Moving Average (MA) methods model $\tilde{z}_{t}$ as a finite sum of $n$ previous shocks $\omega_{t}, \omega_{t-1}, \omega_{t-2}, \ldots \omega_{t-n}$. The Moving Average process of order $n, \operatorname{MA}(n)$, is defined as

$$
\tilde{z}_{t}=\omega_{t}+\theta_{1} \omega_{t-1}+\theta_{2} \omega_{t-2}+\cdots+\theta_{n} \omega_{t-n}
$$

Let us pause here and note that the terminology moving average can be a bit mis-leading due to the fact that the weights in Equation (20) do not, in general, need to be positive nor does their sum necessarily equal unity [81]. Nonetheless, the name is used for historic convention. The $\operatorname{MA}(n)$ operator is defined

$$
\begin{gathered}
\Theta_{n}(q)=\sum_{k=0}^{n} \theta_{k} \hat{q}^{k}=1+\theta_{1} \hat{q}+\theta_{2} \hat{q}^{2}+\cdots+ \\
\theta_{n} \hat{q}^{n}(21)
\end{gathered}
$$

and as a result we can write the MA model in an economic fashion 


$$
\tilde{z}_{t}=\Theta_{n}(q) \omega_{t}
$$

Hence, the MA process can be thought of as the output $\tilde{z}_{t}$ of a linear filter whose transfer function is $\Theta_{n}(q)$, with white noise $\omega_{t}$ as the input.

Like its counterpart, the MA model contains $\mathrm{n}+2$ undetermined parameters $\theta_{1}, \ldots \theta_{n}, \mu, \sigma_{\omega}^{2}$ which must be determined from the data using the techniques described in the next section. Unlike $\mathrm{AR}(m)$ processes, $\mathrm{MA}(n)$ processes do not have a stability condition and, as a result, are unconditionally stable [79].

\section{Mixed Auto-Regressive Moving Average (ARMA) Models}

Linear processes represented by an infinite or an extraneous number of parameters are clearly not practical. However, it is possible to introduce parsimony and still obtain useful models. A well-known result in time series analysis is the relationship between the $\Theta$ weights and $\Phi$ weights [81]. Operating on both sides of Equation (16) by $\Theta(q)$ and making use of Equation (22), yield

$$
\Theta(q) \Phi(q) \tilde{z}_{t}=\Theta(q) \omega_{t}=\tilde{z}_{t}
$$
which implies

$\Theta(q) \Phi(q)=$

$$
1
$$

that is

$$
\Theta(q)
$$

$$
\Phi^{-1}(q)=
$$

Equation (25) indicates that the $\Phi$ weights may be arrived at from knowledge of the $\Theta$ weights, and vice-versa. Thus the finite MA process $\tilde{z}_{t}=\Theta(q) \omega_{t}$ can be written as an infinite AR process

$$
\tilde{z}_{t}=-\theta_{1} \tilde{z}_{t-1}-\theta_{1}^{2} \tilde{z}_{t-2}-\cdots+\omega_{t}(26)
$$

However, if the process were really $\operatorname{MA}(n)$, we would arrive at a non-parsimonious representation in terms of an $\operatorname{AR}(m)$ method. By the same reasoning, an $\operatorname{AR}(m)$ method could not be parsimoniously represented using a $\mathrm{MA}(n)$ process. Therefore, in practice, in order to realize a parameterization which is parsimonious, both AR and MA terms are often used in the model development. Hence,

$$
\begin{gathered}
\tilde{z}_{t}+\phi_{1} \tilde{z}_{t-1}+\cdots+\phi_{m} \tilde{z}_{t-m}= \\
\theta_{n} \omega_{t-n}
\end{gathered}
$$

or

$$
\Phi_{m}(q) \tilde{z}_{t}=\Theta_{n}(q) \omega_{t}
$$

Equation (28) is referred to as the mixed Auto-Regressive Moving Average (ARMA) process of order $(m, n)$. It is illustrative to note that the $\operatorname{ARMA}(m, n)$ process can be written

$$
\tilde{z}_{t}=\frac{\Theta_{n}(q)}{\Phi_{m}(q)} \omega_{t}=\frac{1+\theta_{1} \hat{q}+\cdots+\theta_{n} \hat{q}^{n}}{1+\phi_{1} \hat{q}+\cdots+\phi_{m} \hat{q}^{m}} \omega_{t}
$$

and as a result can be thought of as the output $\tilde{z}_{t}$ from a linear filter, whose transfer function is the ratio of two polynomials $\Theta_{\mathrm{n}}(q)$ and $\Phi_{\mathrm{m}}(B)$, with white noise $\omega_{t}$ as the input.

In practice, it is frequently true that adequate representation of actually occurring stationary time series can be obtained from models in which $\mathrm{n}$ and $\mathrm{m}$ are not greater than two and often less than two $[81,80]$. The order of the model, that is the values of $m$ and $n$, is determined using the sample autocorrelation function and partial auto-correlation function of the time series [83]. The model parameters are estimated by least squares methods and the resulting model is said to adequately contained in the series in a parsimonious manner.

\section{Mixed Auto-Regressive Moving Average Models with Exogenous Variables (ARMAX)}

All of the linear stationary stochastic techniques discusses so far have been univariate; meaning the technique uses previous values of only the time series it is attempting to model. However, the accuracy of $\operatorname{ARMA}(m, n)$ models may be improved by including information external to the time series under analysis. For example, in the case of solar forecasting, the error of a forecasting model may be reduced by including information about the evolution of the local temperature, relative humidity, cloud cover, wind speed, wind direction, etc. Variables such as these, which are independent of the models but affect its value, are referred to as exogenous variables. We can include into the $\operatorname{ARMA}(m, n)$ models $p$ exogenous input terms which allows us to write the $\operatorname{ARMAX}(m, n, p)$ process as

$$
\begin{aligned}
& \tilde{z}_{t}+\phi_{1} \tilde{z}_{t-1}+\cdots+\phi_{m} \tilde{z}_{t-m}=\omega_{t}+\theta_{1} \omega_{t-1}+\cdots+ \\
& \theta_{n} \omega_{t-n}+\lambda_{1} e_{t-1}+\cdots+\lambda_{p} e_{t-p}
\end{aligned}
$$

The above model contains $\operatorname{AR}(m)$ and $\operatorname{MA}(n)$ models as well as the last $p$ values of an exogenous time series $e_{t}$. Defining the exogenous input operator of order $p$ as

$$
\begin{aligned}
& \qquad \Lambda_{p}(q)=\sum_{k=0}^{p} \lambda_{k} \hat{q}^{k}=1+\lambda_{1} \hat{q}+\lambda_{2} \hat{q}^{2}+\cdots+ \\
& \lambda_{p} \hat{q}^{p}(31) \\
& \text { The ARMAX }(m, n, p) \text { model conveniently be written as } \\
& \qquad \Phi_{m}(q) \tilde{z}_{t}=\Theta_{n}(q) \omega_{t}+\Lambda_{p}(q) e_{t}
\end{aligned}
$$

The careful reader might already be aware of the fact that all of the linear stationary models discussed so far have a similar structure. In fact, many models in linear system analysis can be considered a special case of the general discrete time model structure

$$
\Phi(q) \tilde{z}_{t}=\frac{\Theta(q)}{\Psi(q)} \omega_{t}+\frac{\Lambda(q)}{\Xi(q)} e_{t}
$$

where $\Phi(q), \Theta(q), \Lambda(q), \Psi(q)$ and $\Xi(q)$ are polynomials of the shift operator $q[82,84]$.

\subsubsection{Non-Linear Stationary Models}

So far we have only considered general classes of linear stationary models. However, non-linear methods would enable powerful structures with the ability to accurately describe complex nonlinear behaviour such as: chaos, hysteresis and saturation eff ects or a combination of several non-linear problems [84]. A step towards nonlinear modelling is made by introducing the Non-linear AR-exogenous (NARX) model as

$$
\tilde{z}_{t}=f\left(\tilde{z}_{t-1}, \tilde{z}_{t-2}, \ldots, \tilde{z}_{t-m}, e_{t-1}, e_{t-2}, \ldots, e_{t-n}\right)+\omega_{t}
$$

In much the same way one can also convert the ARMAX model into a Non-linear ARMAX model (NARMAX) as follows

$\tilde{z}_{t}=$

$f\left(\tilde{z}_{t-1}, \tilde{z}_{t-2}, \ldots, \tilde{z}_{t-m}, e_{t-1}, e_{t-2}, \ldots, e_{t-n}, \omega_{t-1}, \omega_{t-2}, \ldots, \omega_{t-p}\right)+$ $\omega_{t} \quad(35)$

These non-linear input-output models find many applications in the field of engineering, especially in the parameterization of Artificial Networks.

\subsubsection{Linear Non-Stationary Models}

If the sequence of weights in Equation (12) is infinite but not convergent, the linear filter's transfer function $G(q)$ is said to be unstable and the process $z_{t}$ to be non-stationary. In this case, $\mu$ has no physical meaning except as a reference to the level of the process. Non-stationary processes are diff erent in one or more respects throughout the time series due to the 
time dependent nature of the level. As a result, in the analysis of non-stationary time series, time must play a fundamental role, for example, as the independent variable in a progression function, or as a normalization factor in the analysis of the evolution of a phenomenon from an initial state [79]. Several observed time series behave as if they has no specified mean about which they fluctuate, for example, daily stock prices or hourly readings from a chemical process [81].

\section{Auto-Regressive Integrated Moving Average Models (ARIMA)}

While non-stationary processes do not fluctuate about a static mean, they still display some level of homogeneity to the extent that, besides a difference in local level or trend, diff erent sections of the time series behave in a quite similar way. These non-stationary processes may be modelled by particularizing an appropriate diff erence, for example, the value of the level or slope, as stationary. What follows is a description of an important class of models for which it is assumed that the dth differene is a stationary $\operatorname{ARMA}(m, n)$ process.

We have seen that the stationary condition of an $\operatorname{ARMA}(m, n)$ process is that all roots of $\Phi_{\mathrm{m}}(q)=0$ lie outside the unit circle, and when the roots lie inside the unit circle, the model exhibits non-stationary behaviour. However, we have not discussed the situation for which the roots of $\Phi_{\mathrm{m}}(q)=0$ lie on the unit circle. Let us examine the following ARMA $(m, n)$ model

$$
\Phi_{m}(q) \tilde{z}_{t}=\Theta_{n}(q) \omega_{t}
$$

and specify that $\mathrm{d}$ of the roots of $\Phi_{m}(q)=0$ lie on the unit circle and the residuum lie outside. We can then express the model as

$$
\Phi_{m}(q) \tilde{z}_{t}=\Theta_{n}(q)(1-\hat{q})^{d} \tilde{z}_{t}=\Theta_{n}(q) \omega_{t}
$$

where $\Phi_{m}(q)$ is a stationary and invertible $\operatorname{AR}(m)$ operator. Seeing that $\widetilde{\nabla}^{d} \tilde{z}_{t}=\widetilde{\nabla}^{d} z_{t}$ when $d \geq 1$, we can write

$$
\Phi_{m}(q) \widetilde{\nabla}^{d} \tilde{z}_{t}=\Theta_{n}(q) \omega_{t}
$$

Defining $y_{t}=\widetilde{\nabla}^{d} z_{t}$ allows one to express the model in a more illustrative way

$$
\Phi_{m}(q) y_{t}=\Theta_{n}(q) \omega_{t}
$$

Where it is clear that the model is in agreement with the assumption that the $d^{\text {th }}$ diff erence of the time series can be regarded as a stationary $\operatorname{ARMA}(p, q)$ process. If we not invert Equation (39) we see that

$$
z_{t}=S^{d} y_{t}
$$

Which implies that the process can be arrived at by summing, or integrating, the stationary process $d$ times. Thus, we refer to (38) as the Auto-Regressive Integrated Moving Average (ARIMA) process. Because the AR operator $\Phi_{m}(q)$ is of order $m$, the $d^{\text {th }}$ diff erence is taken and the MA operator $\Theta_{n}(q)$ is of order $n$ in (38) we refer to the process as ARIMA $(m, d, n)$. In practice, $d$ is typically 0,1 or at most 2 [81]. As mentioned above, the ARIMA $(m, d, n)$ model is equivalent to representing the process $z_{t}$ as the output of a linear filter with transfer function $\Phi_{n}^{-1} \widetilde{\nabla}^{-d} \Theta_{n}$ and takes white noise $\omega_{t}$ as an input.

\section{Auto-Regressive Integrated Moving Average Models with Exogenous Variables (ARIMAX)}

In a similar way to the $\operatorname{ARMAX}(m, d, n)$ model, the previous $\mathrm{p}$ values of an exogenous time series $e_{t}$ may also be included into the $\operatorname{ARIMA}(m, d, n)$ model to yield the ARIMAX process of order $(m, d, n, p)$

$$
\begin{aligned}
& \tilde{z}_{t}=\phi_{1} \widetilde{\nabla}^{d} z_{t-1}+\cdots+\phi_{m} \widetilde{\nabla}^{d} z_{t-m}+\omega_{t}+ \\
& \theta_{1} \omega_{t-1}+\cdots+\theta_{n} \omega_{t-n}+\lambda_{1} e_{t-1}+\cdots+ \\
& \lambda_{p} e_{t-p}(41)
\end{aligned}
$$

As we did before, defining $y_{t}=\widetilde{\nabla}^{d} z_{t}$ in terms of the backwards shift operator allows us to express the model in a more compact form

$$
\Phi_{m}(q) y_{t}=\Theta_{n}(q) \omega_{t}+\Lambda_{p}(q) e_{t}
$$

which again looks very similar to Equation (33).

\subsubsection{Persistence Model}

The persistence model is considered as one of the simplest way for forecasting. It basically predicts the future value, assuming it is same as the previous value.

$$
X_{t+1}=X_{t}
$$

It is also known as the naive predictor. It can be used to give a clue to compare with other methods. The persistence model gives good results when the changes in the weather patterns are very little. These models give high error results for forecasting more than one hour.

\subsubsection{Artificial Neural Networks}

The artificial neural network (ANN) is a sub-domain of artificial intelligence (AI).There are many architectures in ANN including multilayer perceptron (MLP), radial basis network, self-organized map, support vector machine and Hopfield networks, and others [149]. These architectures differ from one another greatly. ANNs are however used to perform two types of tasks, which are, regression and pattern recognition. Both these are applied in solar irradiance forecasting.

To define the regression applications, in this inputs are mapped to outputs in a non-linear manner. In this the historical data are used as ANN inputs and irradiance of the immediate time steps is outputs. Therefore, ANN takes two steps, the training and the forecast. In the training phase the weights of the artificial neurons are determined and the forecasts are computed based on the trained weights. Same as regression applications, pattern recognition applications involve training and testing. In this instead of outputting the forecast irradiance, the ANN gives a natural number as output which represents

the object classification.

The irradiance forecasting accuracy is improved by meteorological and climatological inputs such as temperature and humidity. [85] used climatological variables as inputs to an ANN to predict monthly values of global horizontal irradiance (GHI) over a year. Other examples include [86, 87, 88]. 


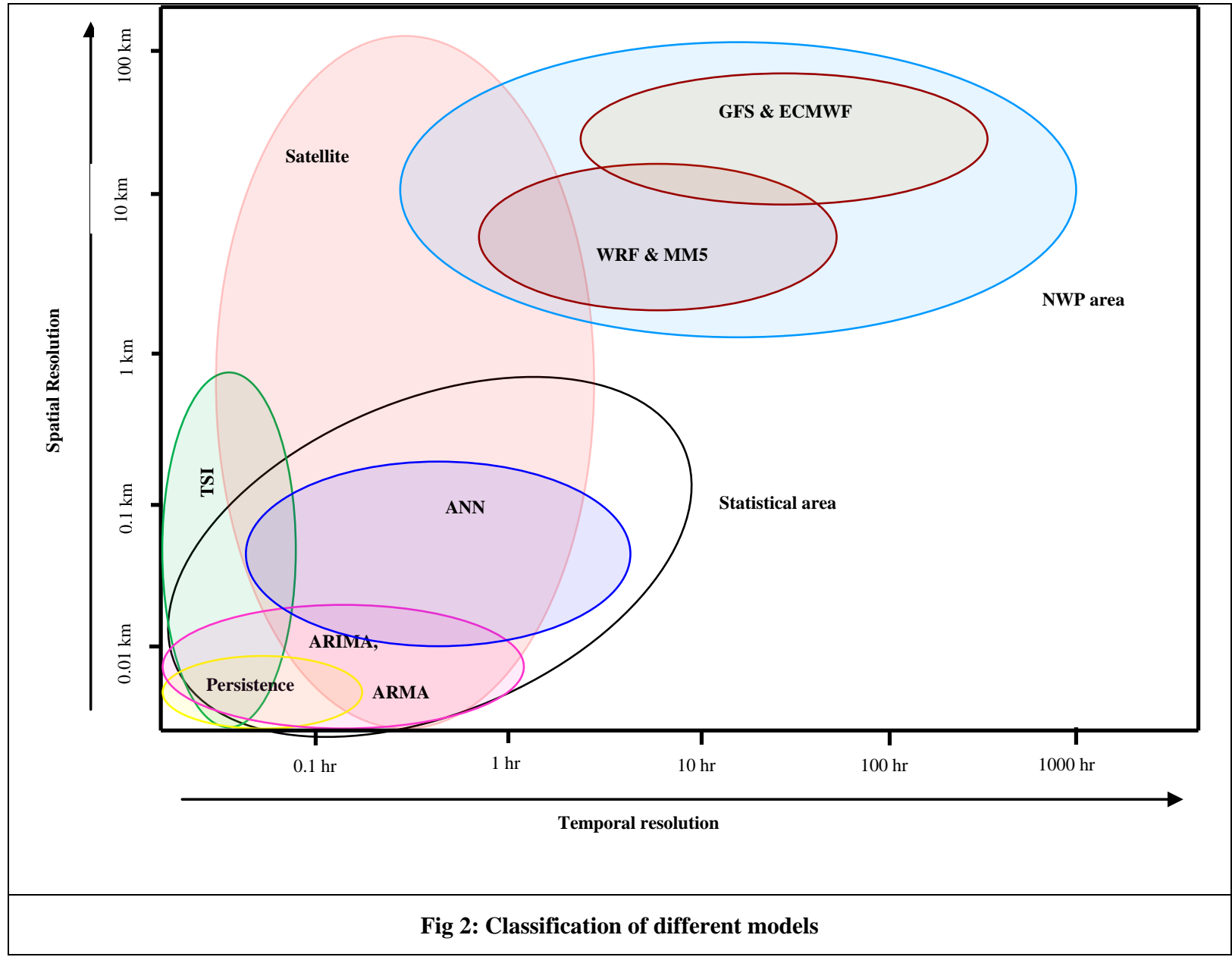

ANN also showed some developments in its fields so as to predict solar irradiance forecasting. Some examples are [89] applied time delayed neural network; [90] applied wavelet neural network. Other similar work includes [69][91-96].

Many researchers publish forecasting results with new data from various regions in the world for archive purpose [97] used MLPs for forecasts for six cities in Iran [98]. Forecast solar irradiance of a grid connected PV plants in Italy. [99] Forecast global radiation in Australia and compared to a few other techniques.

Some work by [100-103] and [98] developed ANN using training data to reduce relative RMSE (rRMSE) of daily average GHI.

\subsection{Hybrid Methods}

Hybrid models are the combination of two or more forecasting techniques so as to improve the accuracy of the forecast. Therefore, they are also known as combined models. The idea behind using the hybrid models is to overcome the deficiencies of the individual models and to utilize the advantages of individual models, merge them together and provide a new hybrid model to reduce forecast errors. For instance, the NWP model can be combined with the ANN by feeding the outputs from the NWP as input to the ANN models. Hybrid models can combine linear models, nonlinear models, or both linear and nonlinear models. Many studies have showed that integrated forecast methods outperform individual forecast [2].
In some studies it is founded that ANN is combined with wavelet to develop a new forecasting method. Cao and Cao [104-108] they all combined wavelet with ANN. Other authors like [109-123] used other soft computing techniques like GA, fuzzy logic, Quantum based GA, adaptive neurofuzzy, etc. to develop hybrid models. In all these models combinations like (fuzzy + ANN), (adaptive neuro fuzzy + ANN), (fuzzy + adaptive neuro-fuzzy + ANN + GNN), (wavelet + fuzzy), etc. are developed. Time series methods are also combined with ANN like in [89] [124-129]. Some other hybrid models include [130] which combined self organized map with exponential smoothing. [131] combined MLP with model output statistics for improving NWP model.

\section{SOLAR FORECASTING EVALUATION METRICS}

For evaluating the performance of a forecast model, the error needs to be calculated. Understanding the forecast error tells us how much to trust the forecast, and re-evaluate the forecasting methods in case of a high error forecast. Solar power metrics can be broadly classified into four categories: [132]

\subsection{Statistical Metrics}

Statistical error measurement differs on the fact whether solar irradiance or solar power forecast is done on daylight hours or on all hours of a day. 


\section{Pearson's correlation coefficient}

Pearson's correlation coefficient is a measure of the correlation between two variables (or sets of data). The Pearson's correlation coefficient, $\rho$, is defined as the covariance of actual and forecast solar power variables divided by the product of their standard deviations, which is mathematically expressed as:

$$
\rho=\frac{\operatorname{cov}(p, \hat{p})}{\sigma_{p} \sigma_{\hat{p}}}
$$

where $p$ and $\hat{p}$ represents the actual and forecast solar power output, respectively. A larger value of Pearson's correlation coefficient indicates an improved solar forecasting skill.

\section{Root mean squared error (RMSE) and normalized root mean squared error ( $n R M S E$ )}

The RMSE also provides a global error measure during the entire forecasting period, which is given by:

$$
R M S E=\sqrt{\frac{1}{N} \sum_{i=1}^{N}\left(\widehat{p}_{i}-p_{i}\right)^{2}}
$$

where $p i$ represents the actual solar power generation at the ith time step, $\widehat{p}_{i}$ is the corresponding solar power generation estimated by a forecasting model, and $\mathrm{N}$ is the number of points estimated in the forecasting period. To compare the results from different spatial and temporal scales of forecast errors, we normalized the RMSE using the capacity value of the analyzed solar plants.

\section{Maximum absolute error (MaxAE), Mean absolute error (MAE), mean absolute percentage error (MAPE), and mean bias error (MBE)}

The MaxAE is an indicative of local deviations of forecast errors, which is given by:

$$
\operatorname{Max} A E=\max _{i=1,2, \ldots N}\left|\widehat{p}_{i}-p_{i}\right|
$$

The MaxAE metric is useful to evaluate the forecasting of short-term extreme events in the power system.

The MAE has been widely used in regression problems and by the renewable energy industry to evaluate forecast performance, which is given by:

$$
M A E=\frac{1}{N} \sum_{i=1}^{N}\left|\widehat{p}_{i}-p_{i}\right|
$$

The MAE metric is also a global error measure metric, which, unlike the RMSE metric, does not excessively account for extreme forecast events.

The MAPE and MBE are expressed as:

$$
M A P E=\frac{1}{N} \sum_{i=1}^{N}\left|\frac{\widehat{p_{i}}-p_{i}}{\text { capacity }}\right|
$$

$$
M B E=\frac{1}{N} \sum_{i=1}^{N}\left(\widehat{p}_{i}-p_{i}\right)
$$

The MBE metric intends to indicate average forecast bias. Understanding the overall forecast bias (over- or underforecasting) would allow power system operators to better allocate resources for compensating forecast errors in the dispatch process.

\section{Kolmogorov-Smirnov test integral (KSI) and OVER metrics}

The KSI and OVER metrics were proposed by [133]. The Kolmogorov-Smirnov (KS) test is a nonparametric test to determine if two data sets are significantly different. The KS statistic D is defined as the maximum value of the absolute difference between two cumulative distribution functions (CDFs), expressed as

$$
D=\max \left|F_{\left(p_{i}\right)}-\widehat{F_{\left(p_{i}\right)}}\right|
$$

Where $F$ and $\hat{F}$ represents the CDFs of actual and forecast solar power generation data sets, respectively. The associated null hypothesis is elaborated as follows: if the D statistic characterizing the difference between one distribution and the reference distribution is lower than the threshold value $V_{c}$, the two data sets have a very similar distribution and could statistically be the same. The critical value $V_{c}$ depends on the number of points in the forecast time series, which is calculated for a $99 \%$ level of confidence [133].

$$
V_{C}=\frac{1.63}{\sqrt{N}} \quad \mathrm{~N} \geq 35
$$

The difference between the CDFs of actual and forecast power is defined for each interval as

$$
\begin{gathered}
D_{j}=\max \left|F_{\left(p_{i}\right)}-\widehat{F_{\left(p_{i}\right)}}\right|, \quad j=1,2,3, . m \\
\text { where } \quad p_{i} \in\left[p_{\min }+(j-1) d, p_{\text {min }}+j d\right]
\end{gathered}
$$

Here the value of $m$ is chosen as 100 , and the interval distance $\mathrm{d}$ is defined as

$$
d=\frac{p_{\max }-p_{\min }}{m}
$$

Where $p_{\max }$ and $p_{\min }$ are the maximum and minimum values of the solar power generation, respectively. The KSI parameter is defined as the integrated difference between the two CDFs, expressed as

$$
K S I=\int_{p_{\min }}^{p_{\max }} D_{n} d p
$$

A smaller value of KSI indicates a better performance of solar power forecasting. A zero KSI index means that the CDFs of two sets are equal. A relative value of KSI is calculated by normalizing the KSI value by

$$
\begin{gathered}
a_{c}=V_{C} *\left(p_{\max }-p_{\min }\right) \\
K S I P \operatorname{Per}(\%)=\frac{K S I}{a_{c}} * 100
\end{gathered}
$$

The OVER metric also characterizes the integrated difference between the CDFs of actual and forecast solar power. The 
OVER metric considers only the points at which the critical value $V_{c}$ is exceeded. The OVER metric and its relative value are given by

$$
\begin{gathered}
\text { OVER }=\int_{p_{\min }}^{p_{\max }} t d p \\
\operatorname{OVERPer}(\%)=\frac{\text { OVER }}{a_{c}} * 100
\end{gathered}
$$

The parameter $t$ is defined by

$$
t=\left\{\begin{array}{cl}
D_{j}-V_{c} & \text { if } D_{j}>V_{c} \\
0 & \text { if } D_{j} \leq V_{c}
\end{array}\right.
$$

As with the KSIPer metric, a smaller value of OVERPer indicates a better performance of the solar power forecasting.

\section{Skewness and kurtosis}

Skewness is a measure of the asymmetry of the probability distribution, and is the third standardized moment, given by:

$$
\gamma=E\left[\left(\frac{e-\mu_{e}}{\sigma_{e}}\right)^{2}\right]
$$

Where $\gamma$ is the skewness; $e$ is the solar power forecast error, which is equal to the forecast minus the actual solar power value; and $\mu_{e}$ and $\sigma_{e}$ are the mean and standard deviation of forecast errors, respectively. Assuming that forecast errors are equal to forecast power minus actual power, a positive skewness of the forecast errors leads to an over-forecasting tail, and a negative skewness leads to an under-forecasting tail.

Kurtosis is a measure of the magnitude of the peak of the distribution, or, conversely, how fat-tailed the distribution is, and is the fourth standardized moment, expressed as:

$$
K=\mu_{4} / \sigma_{e}^{4}-3
$$

Where $K$ is the kurtosis, $\mu_{4}$ is the fourth moment about the mean, and $\sigma$ is the standard deviation of forecast errors. The difference between the kurtosis of a sample distribution and that of the normal distribution is known as the excess kurtosis.

\subsection{Metrics for Uncertainty Quantification and Propagation}

Two metrics are proposed to quantify the uncertainty in solar forecasting, which are: (i) standard deviation of solar power forecast errors; and (ii) Rényi entropy of solar power forecast errors.

\section{Information entropy of forecast errors}

An information entropy approach was proposed in the literature [134-135] for assessing wind forecasting methods.
This information entropy approach based on Rényi entropy is adopted here to quantify the uncertainty in solar forecasting. The Rényi entropy is defined as:

$$
H_{\alpha}(X)=\frac{1}{1-\alpha} \log _{2} \sum_{i=1}^{n} p_{i}^{\alpha}
$$

where $\alpha$ is a parameter that allows the creation of a spectrum of Rényi entropies, and $p_{i}$ is the probability density of the $i^{\text {th }}$ discrete section of the distribution. Large values of $\alpha$ favor higher probability events; whereas smaller values of $\alpha$ weight all of the instances more evenly. A larger value of Rényi entropy indicates a high uncertainty in the forecasting.

\subsection{Metrics for Ramps Characterization}

One of the biggest concerns associated with integrating a large amount of solar power into the grid is the ability to handle large ramps in solar power output, often caused by cloud events and extreme weather events [136]. Different time and geographic scales influence solar ramps, and they can be either up-ramps or down-ramps, with varying levels of severity. The forecasting of solar power can help reduce the uncertainty involved with the power supply.

\section{Swinging door algorithm signal compression}

The swinging door algorithm extracts ramp periods in a series of power signals, by identifying the start and end points of each ramp. The algorithm allows for consideration of a threshold parameter influencing its sensitivity to ramp variations.

\section{Heat Maps}

In addition to the ramp periods identified by the swinging door algorithm, heat maps are adopted to illustrate variations of solar power forecast errors. Heat maps allow for power system operators to observe the timing, duration, and magnitude of ramps together.

\subsection{Economic and Reliability Metrics}

Flexibility reserves have been proposed as a way to compensate for the variability and short-term uncertainty of solar output. Flexibility reserves are the amount of power (in MW) needed to compensate for most hourly or intra-hourly deviations between solar forecasts and actual solar generation values. Improving solar forecasting accuracy is expected to decrease the amount of flexibility reserves that need to be procured with a high penetration of solar power in the system. Flexibility reserves are primarily determined by net load forecast error characteristics [137].

\begin{tabular}{|l|l|l|l|l|l|l|}
\hline \multicolumn{7}{|c|}{ Table 2: Summary of 10 years publications in solar forecasting } \\
\hline Author & \multicolumn{1}{|c|}{ Method } & Horizon & $\begin{array}{l}\text { Performance } \\
\text { Metric }\end{array}$ & Location & Variables & Data Center \\
\hline Perez et al. & Physical & Less & Relative & Albany, & Ambient & National \\
$(2007)$ & (Satellite Based & than 4 & Mean Bias & New York & Temp., dew & Digital \\
& Model) & hr, 4-8 & Error, & & point temp., \\
precipitation, & Forecast \\
Database \\
\end{tabular}




\begin{tabular}{|c|c|c|c|c|c|c|}
\hline & & $76 \mathrm{hr}$ & Error & & $\begin{array}{l}\text { type, sky } \\
\text { cover, wind } \\
\text { speed and } \\
\text { direction, } \\
\text { wave height, } \\
\text { snow amount }\end{array}$ & \\
\hline $\begin{array}{l}\text { Lorenz et } \\
\text { al. (2007) } \\
{[67]} \\
\end{array}$ & Physical & $\begin{array}{l}3 \text { days } \\
\text { ahead }\end{array}$ & $\begin{array}{l}\text { Root Mean } \\
\text { Square Error, } \\
\text { BIAS }\end{array}$ & Germany & - & ECMWF \\
\hline $\begin{array}{c}\text { Cao and } \\
\text { Lin (2008) } \\
{[90]}\end{array}$ & $\begin{array}{l}\text { Statistical } \\
\text { (ANN) }\end{array}$ & $\begin{array}{l}\text { Hourly } \\
\text { and } \\
\text { daily }\end{array}$ & $\begin{array}{l}\text { Root Mean } \\
\text { Square Error, } \\
\text { Mean relative } \\
\text { error }\end{array}$ & $\begin{array}{l}\text { Shanghai } \\
\text { and Macau }\end{array}$ & Cloud cover & $\begin{array}{l}\text { Data from } \\
\text { Baoshan } \\
\text { Meteorological } \\
\text { Observatory, } \\
\text { Shanghai }\end{array}$ \\
\hline $\begin{array}{l}\text { Hacaoglu et } \\
\text { al. (2008) } \\
{[138]}\end{array}$ & $\begin{array}{l}\text { Statistical } \\
\text { (ANN) }\end{array}$ & Hourly & $\begin{array}{l}\text { Root Mean } \\
\text { Square Error }\end{array}$ & $\begin{array}{l}\text { Eylul, } \\
\text { Turkey }\end{array}$ & - & $\begin{array}{l}1 \text { yr data from } \\
\text { Iki Eylul, } \\
\text { Turkey }\end{array}$ \\
\hline $\begin{array}{l}\text { Remund et } \\
\text { al. (2008) } \\
\quad[71]\end{array}$ & Physical & 3 hours & $\begin{array}{l}\text { Mean Bias } \\
\text { Error and } \\
\text { Root Mean } \\
\text { Square Error }\end{array}$ & $\begin{array}{l}\text { USA, } \\
\text { Germany, } \\
\text { Switzerland }\end{array}$ & - & $\begin{array}{l}\text { National } \\
\text { Digital } \\
\text { Forecast } \\
\text { Database } \\
\end{array}$ \\
\hline $\begin{array}{c}\text { Bacher et } \\
\text { al. (2009) } \\
{[139]}\end{array}$ & $\begin{array}{l}\text { Statistical (Time } \\
\text { Series Model) }\end{array}$ & Hourly & $\begin{array}{l}\text { Root Mean } \\
\text { Square Error }\end{array}$ & Denmark & - & $\begin{array}{l}\text { Danish } \\
\text { Meteorological } \\
\text { Institute }\end{array}$ \\
\hline $\begin{array}{l}\text { Lorenz et } \\
\text { al. (2009) } \\
\text { [61] }\end{array}$ & Physical & $\begin{array}{l}1 \mathrm{hr} \text { to } \\
\text { 3days }\end{array}$ & $\begin{array}{l}\text { Relative Root } \\
\text { Mean Square } \\
\text { Error }\end{array}$ & Germany & - & ECMWF \\
\hline $\begin{array}{l}\text { Reikard } \\
\text { (2009) } \\
\\
{[125]}\end{array}$ & $\begin{array}{l}\text { Hybrid (Time } \\
\text { Series + ANN) }\end{array}$ & $\begin{array}{l}5,15,30 \\
\text { min and } \\
1-4 \mathrm{hr}\end{array}$ & & USA & $\begin{array}{l}\text { Humidity, } \\
\text { cloud cover, } \\
\text { atmospheric } \\
\text { turbulence }\end{array}$ & $\begin{array}{l}\text { National Solar } \\
\text { Radiation } \\
\text { Database, } \\
\text { Solar } \\
\text { Radiation } \\
\text { Research } \\
\text { Laboratory, } \\
\text { National Wind } \\
\text { Technology } \\
\text { Laboratory } \\
\end{array}$ \\
\hline $\begin{array}{l}\text { Azadeh et } \\
\text { al. (2009) } \\
\qquad \text { [97] }\end{array}$ & $\begin{array}{l}\text { Statistical } \\
\text { (ANN) }\end{array}$ & - & $\begin{array}{l}\text { Mean } \\
\text { Absolute } \\
\text { Percentage } \\
\text { Error }\end{array}$ & Iran & $\begin{array}{l}\text { Wind speed, } \\
\text { vapour } \\
\text { pressure, } \\
\text { humidity, } \\
\text { temp., } \\
\text { location, } \\
\text { month }\end{array}$ & $\begin{array}{l}\text { Data from six } \\
\text { cities in Iran }\end{array}$ \\
\hline $\begin{array}{l}\text { Mellit and } \\
\text { Pavan } \\
(2010) \\
{[98]} \\
\end{array}$ & $\begin{array}{l}\text { Statistical } \\
\text { (ANN) }\end{array}$ & $24 \mathrm{hr}$ & $\begin{array}{l}\text { Mean Bias } \\
\text { Error, Root } \\
\text { Mean Square } \\
\text { Error }\end{array}$ & $\begin{array}{l}\text { Trieste, } \\
\text { Italy }\end{array}$ & - & $\begin{array}{l}\text { Data from } \\
\text { municipality } \\
\text { of Trieste }\end{array}$ \\
\hline $\begin{array}{l}\text { Perez et al. } \\
\text { (2010) } \\
\text { [72] }\end{array}$ & Physical & $\begin{array}{l}1-6 \mathrm{hr} \\
\text { and 1-7 } \\
\text {-days }\end{array}$ & $\begin{array}{l}\text { KSI, OVER, } \\
\text { Mean Bias } \\
\text { Error, Root } \\
\text { Mean Square } \\
\text { Error }\end{array}$ & USA & Cloud cover & $\begin{array}{l}1 \text { yr of hourly } \\
\text { data from the } \\
\text { SURFRAD } \\
\text { network }\end{array}$ \\
\hline $\begin{array}{l}\text { Martin et } \\
\text { al. (2010) } \\
\qquad[140]\end{array}$ & $\begin{array}{l}\text { Statistical (AR, } \\
\text { ANN, Fuzzy) }\end{array}$ & $\begin{array}{l}\text { Out to } 3 \\
\text { days }\end{array}$ & $\begin{array}{l}\text { Relative Root } \\
\text { Mean Square } \\
\text { Deviation }\end{array}$ & Spain & - & $\begin{array}{l}\text { Spanish } \\
\text { National } \\
\text { Weather } \\
\text { Service, Spain }\end{array}$ \\
\hline $\begin{array}{l}\text { Mellit et al. } \\
(2010) \\
{[141]}\end{array}$ & $\begin{array}{ll}\text { Statistical } & \text { (AR } \\
\text { and ANN) } & \end{array}$ & Hourly & $\begin{array}{l}\text { Correlation } \\
\text { coefficient, } \\
\text { Mean Bias } \\
\text { Error }\end{array}$ & $\begin{array}{l}\text { Saudi } \\
\text { Arabia }\end{array}$ & $\begin{array}{l}\text { Sunshine } \\
\text { duration, air } \\
\text { temp., } \\
\text { humidity } \\
\end{array}$ & $\begin{array}{l}\text { 5yr data from } \\
\text { Jeddah site, } \\
\text { Saudi Arabia }\end{array}$ \\
\hline $\begin{array}{l}\text { Paoli et al. } \\
\text { (2010) } \\
\text { [142] }\end{array}$ & $\begin{array}{l}\text { Hybrid (kNN, } \\
\text { ANN, AR, } \\
\text { Markov Chain, } \\
\text { Bayesian } \\
\text { Inference) } \\
\end{array}$ & 1 day & $\begin{array}{l}\text { Root Mean } \\
\text { Square Error, } \\
\text { normalized } \\
\text { Root Mean } \\
\text { Square Error }\end{array}$ & France & - & $\begin{array}{l}19 \text { yrs of data } \\
\text { from } \\
\text { meteorological } \\
\text { station of } \\
\text { Ajaccio, }\end{array}$ \\
\hline
\end{tabular}




\begin{tabular}{|c|c|c|c|c|c|c|}
\hline & & & & & & France \\
\hline $\begin{array}{l}\text { Marquez } \\
\text { and } \\
\text { Coimbra } \\
(2011) \\
\quad[143]\end{array}$ & $\begin{array}{l}\text { Statistical } \\
\text { (ANN) }\end{array}$ & $1 \mathrm{hr}$ & $\begin{array}{l}\text { Mean Bias } \\
\text { Error, Root } \\
\text { Mean Square } \\
\text { Error }\end{array}$ & US & $\begin{array}{l}\text { Sky cover, } \\
\text { precipitation, } \\
\text { temperatures }\end{array}$ & $\begin{array}{l}\text { Data from US } \\
\text { National } \\
\text { Weather } \\
\text { Service }\end{array}$ \\
\hline $\begin{array}{l}\text { Chen et al. } \\
\text { (2011) } \\
\text { [127] }\end{array}$ & $\begin{array}{l}\text { Hybrid (NWP+ } \\
\text { ANN) }\end{array}$ & $24 \mathrm{hr}$ & $\begin{array}{l}\text { Mean } \\
\text { Absolute } \\
\text { Percentage } \\
\text { Error, }\end{array}$ & China & $\begin{array}{l}\text { Relative } \\
\text { humidity, } \\
\text { temperature, } \\
\text { wind speed, } \\
\text { wind } \\
\text { direction, } \\
\text { cloud, } \\
\text { sunshine } \\
\text { duration, air } \\
\text { pressure }\end{array}$ & $\begin{array}{l}\text { Data from } \\
\text { Renewable } \\
\text { Energy } \\
\text { Research } \\
\text { Center of } \\
\text { Huazhong } \\
\text { University of } \\
\text { Science and } \\
\text { Technology }\end{array}$ \\
\hline $\begin{array}{l}\text { Chow et al. } \\
\text { (2011) } \\
\text { [37] }\end{array}$ & Physical & $\begin{array}{l}30 \mathrm{sec} \\
\text { to } 5 \mathrm{~min}\end{array}$ & $\begin{array}{l}\text { Mean, } \\
\text { Standard } \\
\text { Deviation }\end{array}$ & San Diego & - & $\begin{array}{l}\text { University of } \\
\text { California, San } \\
\text { Diego }\end{array}$ \\
\hline $\begin{array}{l}\text { Mathiesen } \\
\text { and Kleissl } \\
\text { (2011) } \\
{[65]}\end{array}$ & Physical & $\begin{array}{l}1 \mathrm{hr} \text { to } 1 \\
\text { day }\end{array}$ & $\begin{array}{l}\text { Mean Bias } \\
\text { Error, Root } \\
\text { Mean Square } \\
\text { Error }\end{array}$ & USA & - & $\begin{array}{l}\text { Hourly data } \\
\text { from } \\
\text { SURFRAD } \\
\text { network, USA }\end{array}$ \\
\hline $\begin{array}{l}\text { Voyant et } \\
\text { al. (2011) } \\
\qquad[126]\end{array}$ & $\begin{array}{l}\text { Hybrid (Time } \\
\text { Series + ANN) }\end{array}$ & 1 day & $\begin{array}{l}\text { Normalized } \\
\text { Root Mean } \\
\text { Square Error }\end{array}$ & France & $\begin{array}{l}\text { Pressure, } \\
\text { nebulosity, } \\
\text { humidity, } \\
\text { wind speed }\end{array}$ & $\begin{array}{l}9 \text { yrs data from } \\
\text { the French } \\
\text { Meteorological } \\
\text { Organization } \\
\text { Corsica, } \\
\text { France }\end{array}$ \\
\hline $\begin{array}{l}\text { Wu and } \\
\text { Chee } \\
(2011) \\
\quad[89] \\
\end{array}$ & $\begin{array}{l}\text { Hybrid (ARMA } \\
+ \text { ANN) }\end{array}$ & 1 hour & $\begin{array}{l}\text { Normalized } \\
\text { Root Mean } \\
\text { Square Error, } \\
\text { Root Mean } \\
\text { Square Error }\end{array}$ & Singapore & - & $\begin{array}{l}1 \text { yr data from } \\
\text { Nanyang } \\
\text { Technological } \\
\text { University, } \\
\text { Singapore }\end{array}$ \\
\hline $\begin{array}{l}\text { Capizzi et } \\
\text { al. (2012) } \\
\qquad[86]\end{array}$ & $\begin{array}{l}\text { Statistical } \\
\text { (ANN) }\end{array}$ & 1 day & $\begin{array}{l}\text { Mean Square } \\
\text { Error, Root } \\
\text { Mean Square } \\
\text { Error }\end{array}$ & Italy & $\begin{array}{l}\text { Wind speed, } \\
\text { humidity and } \\
\text { temp. }\end{array}$ & $\begin{array}{l}1 \text { yr data from } \\
\text { Catania, Italy }\end{array}$ \\
\hline $\begin{array}{l}\text { Boata and } \\
\text { Gravila } \\
(2012)\end{array}$ & $\begin{array}{l}\text { Statistical } \\
\text { (Fuzzy) }\end{array}$ & Daily & $\begin{array}{l}\text { Mean } \\
\text { Absolute } \\
\text { Error, Root } \\
\text { Mean Square } \\
\text { Error, Mean } \\
\text { Bias Error } \\
\end{array}$ & Europe & - & $\begin{array}{l}\text { World } \\
\text { Radiation Data } \\
\text { Center, Russia }\end{array}$ \\
\hline $\begin{array}{l}\text { Mandal et } \\
\text { al. (2012) } \\
\qquad[106]\end{array}$ & $\begin{array}{l}\text { Hybrid } \\
\text { (Wavelet+ANN) }\end{array}$ & 1 hour & $\begin{array}{l}\text { Mean } \\
\text { Absolute } \\
\text { Percentage } \\
\text { Error, Mean } \\
\text { Absolute } \\
\text { Error, Root } \\
\text { Mean Square } \\
\text { Error }\end{array}$ & USA & Temperature & $\begin{array}{l}1 \text { yr data from } \\
\text { Oregon, USA }\end{array}$ \\
\hline $\begin{array}{l}\text { Yap and } \\
\text { Karri } \\
(2012) \\
\quad \text { [99] }\end{array}$ & Statistical & 1 month & $\begin{array}{l}\text { Root Mean } \\
\text { Square Error }\end{array}$ & Australia & $\begin{array}{l}\text { Temperature, } \\
\text { Rainfall, } \\
\text { evaporation, } \\
\text { sunshine } \\
\text { hours }\end{array}$ & $\begin{array}{l}12 \text { yrs } \\
\text { meteorological } \\
\text { data for } \\
\text { Darwin, } \\
\text { Australia } \\
\end{array}$ \\
\hline $\begin{array}{l}\text { Pedro and } \\
\text { Coimbra } \\
(2012) \\
\quad[128]\end{array}$ & Hybrid & $\begin{array}{l}1 \text { and } 2 \\
h r\end{array}$ & $\begin{array}{l}\text { Mean } \\
\text { Absolute } \\
\text { Error, Mean } \\
\text { Bias Error, } \\
\text { Coefficient } \\
\text { of correlation }\end{array}$ & USA & - & $\begin{array}{l}1 \text { yr data from } \\
\text { farm in } \\
\text { Merced, USA }\end{array}$ \\
\hline $\begin{array}{l}\text { Voyant et } \\
\text { al. (2012) } \\
{[144]}\end{array}$ & $\begin{array}{l}\text { Hybrid } \\
\text { (ARMA+ANN) }\end{array}$ & $1 \mathrm{hr}$ & $\begin{array}{l}\text { Normalized } \\
\text { Root Mean } \\
\text { Square Error }\end{array}$ & France & - & $\begin{array}{l}6 \text { yrs data from } \\
\text { Mediterranean, } \\
\text { France }\end{array}$ \\
\hline
\end{tabular}




\begin{tabular}{|c|c|c|c|c|c|c|}
\hline $\begin{array}{l}\text { Marquez et } \\
\text { al. (2013) } \\
\qquad[40]\end{array}$ & $\begin{array}{l}\text { Hybrid } \\
\text { (Satellite+ANN) }\end{array}$ & $\begin{array}{l}30,60, \\
90,120 \\
\min \end{array}$ & $\begin{array}{l}\text { Root Mean } \\
\text { Square Error, } \\
\text { Mean Bias } \\
\text { Error }\end{array}$ & USA & - & $\begin{array}{l}1 \text { yr data for } \\
\text { Davis and } \\
\text { Merced and } \\
\text { hourly } \\
\text { NOAA's } \\
\text { GOES West } \\
\text { satellite } \\
\text { images, USA }\end{array}$ \\
\hline $\begin{array}{l}\text { Marquez et } \\
\text { al. (2013) } \\
\qquad[145]\end{array}$ & $\begin{array}{l}\text { Hybrid } \\
\text { (ANN+Sky } \\
\text { images) }\end{array}$ & $1 \mathrm{hr}$ & $\begin{array}{l}\text { Mean Bias } \\
\text { Error, Root } \\
\text { Mean Square } \\
\text { Error, }\end{array}$ & USA & $\begin{array}{l}\text { Cloud cover, } \\
\text { infrared } \\
\text { radiation, } \\
\text { sky-images }\end{array}$ & $\begin{array}{l}2 \text { months } \\
\text { infrared } \\
\text { radiation and } \\
\text { sky-images } \\
\text { data for } \\
\text { Merced, USA }\end{array}$ \\
\hline $\begin{array}{l}\text { Marquez } \\
\text { and } \\
\text { Coimbra } \\
(2013) \\
\quad[146]\end{array}$ & Physical & $\begin{array}{l}3-15 \\
\min \end{array}$ & $\begin{array}{l}\text { Root Mean } \\
\text { Square Error }\end{array}$ & USA & Cloud cover & $\begin{array}{l}\text { Several days } \\
\text { sky-images } \\
\text { data for } \\
\text { Merced, USA }\end{array}$ \\
\hline $\begin{array}{l}\text { Bosch et al. } \\
(2013) \\
{[147]}\end{array}$ & $\begin{array}{l}\text { Statistical } \\
\text { (Sensor } \\
\text { Network) } \\
\end{array}$ & - & - & USA & - & $\begin{array}{l}\text { Several days } \\
\text { data for San } \\
\text { Diego, USA }\end{array}$ \\
\hline $\begin{array}{l}\text { Voyant et } \\
\text { al. }(2013) \\
\quad[148]\end{array}$ & $\begin{array}{l}\text { Hybrid (ANN+ } \\
\text { ARMA) }\end{array}$ & $1 \mathrm{hr}$ & $\begin{array}{l}\text { Normalized } \\
\text { Root Mean } \\
\text { Square Error }\end{array}$ & France & $\begin{array}{l}\text { Nebulosity, } \\
\text { pressure, } \\
\text { precipitation }\end{array}$ & $\begin{array}{l}10 \text { yrs data } \\
\text { from } \\
\text { Mediterranean, } \\
\text { France }\end{array}$ \\
\hline $\begin{array}{l}\text { Mathiesen } \\
\text { et al. (2013) } \\
\text { [62] }\end{array}$ & Physical & Hourly & $\begin{array}{l}\text { Relative } \\
\text { Mean Bias } \\
\text { Error, } \\
\text { Relative } \\
\text { Mean } \\
\text { Absolute } \\
\text { Error, } \\
\text { Relative Root } \\
\text { Mean Square } \\
\text { Error, } \\
\text { Relative } \\
\text { Standard } \\
\text { Error } \\
\end{array}$ & San Diego & $\begin{array}{l}\text { Wind speed, } \\
\text { wind } \\
\text { direction, } \\
\text { temperature, } \\
\text { precipitation }\end{array}$ & $\begin{array}{l}\text { Data from } \\
\text { University of } \\
\text { California, San } \\
\text { Diego }\end{array}$ \\
\hline $\begin{array}{l}\text { Bernecker } \\
\text { et al. (2014) } \\
{[42]}\end{array}$ & Physical & $10 \mathrm{~min}$ & $\begin{array}{l}\text { Root Mean } \\
\text { Square Error }\end{array}$ & Germany & Cloud speed & $\begin{array}{l}15 \text { days data } \\
\text { collected in } \\
\text { Kitzingen, } \\
\text { Bavaria, } \\
\text { Germany } \\
\end{array}$ \\
\hline $\begin{array}{c}\text { Chu et al. } \\
\text { (2014) } \\
\text { [39] }\end{array}$ & $\begin{array}{lr}\text { Hybrid } & (\text { Sky } \\
\text { Imagery+ } & \text { ANN })\end{array}$ & $\begin{array}{l}5,10,15 \\
\min \end{array}$ & $\begin{array}{l}\text { Mean Bias } \\
\text { Error, Root } \\
\text { Mean Square } \\
\text { Error }\end{array}$ & US & Cloud cover & $\begin{array}{l}\text { Satellite } \\
\text { images from } \\
\text { National } \\
\text { Oceanic and } \\
\text { Atmospheric } \\
\text { Administration }\end{array}$ \\
\hline $\begin{array}{l}\text { Cros et al. } \\
\text { (2014) } \\
{[53]}\end{array}$ & Physical & $4 \mathrm{hr}$ & $\begin{array}{l}\text { Relative Root } \\
\text { Mean Square } \\
\text { Error }\end{array}$ & $\begin{array}{l}\text { France, } \\
\text { Spain }\end{array}$ & Cloudiness & $\begin{array}{l}\text { Satellite } \\
\text { images from } \\
\text { European } \\
\text { Organisation } \\
\text { for the } \\
\text { Exploitation of } \\
\text { Meteorological } \\
\text { Satellites }\end{array}$ \\
\hline $\begin{array}{l}\text { Amrouche } \\
\text { and Pivert } \\
(2014) \\
\text { [150] }\end{array}$ & $\begin{array}{l}\text { Statistical } \\
\text { (ANN) }\end{array}$ & 1 day & $\begin{array}{l}\text { Mean Square } \\
\text { Error, Root } \\
\text { Mean Square } \\
\text { Error }\end{array}$ & France & Temperature & $\begin{array}{l}\text { US National } \\
\text { Oceanic and } \\
\text { Atmospheric } \\
\text { Administration }\end{array}$ \\
\hline $\begin{array}{l}\text { Chaturvedi } \\
\text { (2015) }\end{array}$ & $\begin{array}{l}\text { Hybrid } \\
\text { (Quantum+ GA) }\end{array}$ & $1 \mathrm{~min}$ & $\begin{array}{l}\text { Root Mean } \\
\text { Square Error }\end{array}$ & India & - & $\begin{array}{l}\text { Data from } \\
\text { Faculty of } \\
\text { Engineering, }\end{array}$ \\
\hline
\end{tabular}




\begin{tabular}{|c|c|c|c|c|c|c|}
\hline [109] & & & & & & $\begin{array}{l}\text { Dayal Bagh } \\
\text { Educational } \\
\text { Institute, Agra, } \\
\text { India }\end{array}$ \\
\hline $\begin{array}{c}\text { Chu et al. } \\
\text { (2015) } \\
\text { [50] }\end{array}$ & $\begin{array}{l}\text { Statistical } \\
\text { (ANN) }\end{array}$ & $\begin{array}{l}5,10,15 \\
\min \end{array}$ & $\begin{array}{l}\text { Mean Bias } \\
\text { Error, Mean } \\
\text { Absolute } \\
\text { Error, Root } \\
\text { Mean Square } \\
\text { Error, } \\
\text { Standard } \\
\text { Deviation, } \\
\text { Skewness, } \\
\text { Kurtosis } \\
\end{array}$ & Nevada & - & $\begin{array}{l}\text { Data from the } \\
\text { Sempra } \\
\text { Generation } \\
\text { Copper } \\
\text { Mountain } \\
\text { Solar Power } \\
\text { Plant }\end{array}$ \\
\hline $\begin{array}{c}\text { Ghayekhloo } \\
\text { et al. (2015) } \\
\text { [151] }\end{array}$ & Hybrid & $1 \mathrm{hr}$ & $\begin{array}{l}\text { Mean } \\
\text { Absolute } \\
\text { error, relative } \\
\text { Mean } \\
\text { Absolute } \\
\text { Error, Root } \\
\text { Mean Square } \\
\text { Error, } \\
\text { relative Mean } \\
\text { Absolute } \\
\text { Error }\end{array}$ & $\begin{array}{l}\text { United } \\
\text { States }\end{array}$ & $\begin{array}{l}\text { Temperature, } \\
\text { wind speed, } \\
\text { wind } \\
\text { direction }\end{array}$ & $\begin{array}{l}\text { Hourly data of } \\
\text { Ames Station, } \\
\text { United States }\end{array}$ \\
\hline $\begin{array}{l}\text { Akarslan } \\
\text { and } \\
\text { Hocaoghu } \\
(2016) \\
\quad[152]\end{array}$ & Hybrid & $1 \mathrm{hr}$ & $\begin{array}{l}\text { Root Mean } \\
\text { Square Error, } \\
\text { Mean Bias } \\
\text { Error }\end{array}$ & Turkey & - & $\begin{array}{l}\text { Data from } \\
\text { Turkish State } \\
\text { Meteorological } \\
\text { Service }\end{array}$ \\
\hline $\begin{array}{l}\text { Sharma et } \\
\text { al. (2016) } \\
\qquad[154]\end{array}$ & $\begin{array}{l}\text { Hybrid (sensor+ } \\
\text { wavelet+ ANN) }\end{array}$ & $\begin{array}{l}1 \mathrm{hr}, 15 \\
\text { min }\end{array}$ & $\begin{array}{l}\text { Mean Bias } \\
\text { Error, } \\
\text { Normalized } \\
\text { Root Mean } \\
\text { Square Error }\end{array}$ & Singapore & - & $\begin{array}{l}1 \mathrm{hr} \text { data from } \\
\text { National } \\
\text { University of } \\
\text { Singapore }\end{array}$ \\
\hline $\begin{array}{l}\text { Gala et al. } \\
\text { (2016) } \\
\text { [153] }\end{array}$ & $\begin{array}{l}\text { Hybrid (NWP+ } \\
\text { Machine } \\
\text { Learning) }\end{array}$ & $3 \mathrm{hr}$ & $\begin{array}{l}\text { Mean } \\
\text { Absolute } \\
\text { Error }\end{array}$ & Spain & - & $\begin{array}{l}\text { Data from } \\
\text { Departamento } \\
\text { de } \\
\text { Aplicaciones } \\
\text { para la } \\
\text { Operacion of } \\
\text { Red Electrica } \\
\text { de Espana. }\end{array}$ \\
\hline
\end{tabular}

\section{CONCLUSION}

Various solar forecasting methods and evaluation metrics are discussed in this work. From the study it is found that a variety of work has been performed by various authors for a number of different spatial and temporal resolutions.

The study here is done according to various forecasting methods. In case of physical methods different cloud imagery and satellite based models are studied. Apart from these two total sky imagers and NWP models are also the part of physical methods. Satellite imaging based methods is used as alternatives to expensive ground based pyrometer networks. These are best for forecasting of irradiance in environments where no other data is available. The only disadvantage of these methods is that they suffer from temporal and spatial limitations due to satellite sampling frequency and limits on spatial resolution of the satellite images. NWP is also used for locations without extensive ground networks. These are best option for long term forecasting with horizon from few hours to couple of days or more.
In case of statistical methods different time series and learning methods are studied. In time series methods sequence of observations are measured over time. These methods have models like AR, MA, ARMA, ARMAX, ARIMA etc. And in learning methods various artificial techniques are considered like neural networks, genetic algorithm etc. Artificial Neural Network is discussed which provides good performance for irradiance data when enough historical data is available. These are used for forecasting intra-hour to yearly time horizons. ANNs are generic non-linear approximators that deliver compact solutions for several non-linear, stochastic and multivariate problems.

Nowadays, the most used method is the hybrid method which incorporates two or more techniques and produces a new forecasting method with improved accuracy. In this method the deficiencies of the individual model are overcome and advantages of individual models are utilized. These methods also reduce the forecast errors. For evaluating the forecast errors solar forecasting evaluation metrics are also studied. Forecasting evaluation metrics allow to understand how much to trust the forecast and re-evaluate it in case of high errors. 


\section{REFERENCES}

[1] V Kostylev and A. Pavlovski, "Solar Power Forecasting Performance Towards Industry Standards", Proc. 1st Int. Workshop on Integration of Solar Power into Power Systems, Aarhus, Denmark.

[2] H M Diagne, M David, P Lauret, J Boland and N. Schmutz., "Review of solar irradiance forecasting methods and a proposition for smallscale insular grids", Renew. Sustain. Energy Rev., vol. 27, pp. 65-76, Nov, 2013.

[3] M Noia, C Ratto and R. Festa, "Solar irradiance estimation from geostationary satellite data: II. Physical models", Solar Energy, vol. 51, no. 6, pp. 457 - 465, 1993.

[4] C. Gautier, G Diak and S. Masse, "A Simple Physical Model to Estimate Incident Solar Radiation at the Surface from GOES Satellite Data", Journal of Applied Meteorology, vol. 19, no. 8, pp. 1005-1012, 1980.

[5] C. Raphael, "Models for estimating solar irradiance at the Earth's surface from satellite data: An initial assessment", Technical Report, Atmospheric Environment Service. (Unpublished Manucript), 1983.

[6] C. Raphael . and J. E. Hay, "An assessment of models which use satellite data to estimate solar irradiance at the earth's surface", Joural of Climate and Applied Meteorology, vol. 23, no. 5, pp. 832-844, 1984.

[7] M. Noia, C Ratto, and R. Festa, "Solar irradiance estimation from geostationary satellite data: I. statistical models", Solar Energy, vol. 51, no. 6, pp. 449 - 456, 1993.

[8] K. Coulson, "Characteristics of the radiation emerging from the top of a rayleigh atmosphere-I: Intensity and polarization, Planetary and Space Science", vol. 1, no. 4, pp. $265-276,1959$.

[9] K. Coulson, "Characteristics of the radiation emerging from the top of a Rayleigh atmosphere-II: Total upward flux and albedo, Planetary and Space Science", vol. 1, no. 4, pp. 277 - 284, 1959.

[10] G. W. Paltridge, "Direct measurements of water vapour absorption of solar radiation in the three atmosphere", J. of Applied Meteorology, vol. 30, pp. 156-160, 1973.

[11] C Gautier and R. Frouin, "Downward longwave irradiance at the ocean surface using satellite data: Methodology and in situ validation", J. of Geophysical Research, vol. 93, pp. 597-598, 1985.

[12] D Tanr`e, M Herman, P Y Deschamps and A. DeLeff e, "Atmospheric modeling for space measurements of fround relectances, including bidirectional properties", Applied Optics, vol. 18, pp. 3587-3594, 1979.

[13] S Marullo, G Dalu and A. Viola, "Incident short-wave radiation at the surface from METEOSAT data," Il Nuovo cimento della Societ'a italiana di fisica, vol. 10, no. 1 , pp. $77-90,1987$.

[14] J. Schmetz, "On the parameterization of the radiative properties of broken clouds", Tellus. Series A, Dynamic meteorology and oceanography, vol. 36A, no. 5, pp. $417-417,1984$
[15] W Mo"ser and E. Raschke, "Incident Solar Radiation over Europe Estimated from METEOSAT Data", J. of Climate and Applied Meteorology, vol. 23, no. 1, pp. $166-170,1984$

[16] M Kerschegens, U Pilz, and E. Raschke, "A modified two stream approcimation for computations of the solar radiation budget in a couldy atmosphere", Tellus. Series A, Dynamic meteorology and oceanography, vol. 30, pp. 429-429,1978.

[17] G Dedieu, P Y Deschamps, and Y. H. Kerr, "Satellite Estimation of Solar Irradiance at the Surface of the Earth and of Surface Albedo Using a Physical Model Applied to METEOSAT Data", J. of Climate and Applied Meteorology, vol. 26, no. 1, pp. 79-79,1987.

[18] A. A. Lacis and J. Hansen, "A Parameterization for the Absorption of Solar Radiation in the Earth's Atmosphere", J. of the Atmospheric Sciences, vol. 31, no. 1 , pp. $118-133,1974$.

[19] P. Ineichen, "Comparison of eight clear sky broadband models against 16 independent data banks", Solar Energy, vol. 80, no. 4, pp. 468-478, 2006.

[20] B Molineaux, P Ineichen and N. O’Neill, "Equivalence of pyrheliometric and monochromatic aerosol optical depths at a single key wavelength", Applied Optics, vol. 37, pp. 7008-7018, 1998.

[21] J E Hay and K. J. Hanson, "A satellite-based methodology for determining solar irradiance at the ocean surface durring GATE", Bulletin of the American Meteorological Society, vol. 59, pp. 1549-1549, 1978.

[22] J. D. Tarpley, "Estimating incident solar radiation at the surface from geostationary satellite data", J. of Applied Meteorology, vol. 18, no. 9, pp. 1172-1181,1979.

[23] C Raphael and J. E. Hay, "An assessment of models which use satellite data to estimate solar irradiance at the earth's surface", J. of Climate and Applied Meteorology, vol. 23 , no. 5, pp. 832-844,1984.

[24] C G Justus, M V Paris, and J. D. Tarpley, "Satellitemeasured insolation in the united states, mexico, and south America", Remote Sensing of Environment, vol. 20, pp. 57-83, 1986.

[25] D. Cano, Etude de l'Ennuagement par Analyse de S'equences d'Images de Satellite. Application 'a l'Evaluation du Rayonnement Solaire Gloibal au Sol. $\mathrm{PhD}$ thesis, Ecole Nationale Sup'erieure des t'el'ecommunications, 1982

[26] C Rigollier, O Bauer, and L. Wald, "On the clear sky model of the ESRA - European Solar Radiation Atlas With respect to the Heliosat method", Solar Energy, vol. 68 , pp. 33-48, 2000.

[27] G. Bourges, Courbes de Frequence Cumulees de l'Irradiation Solaire Globale Horaire Recue par une Surface Plane, tech. rep., Centre d'Energetique de l'Ecole National Superieur des Mines de Paris, 1979.

[28] C. Rigollier, "The method HELIOSAT-2 for deriving shortwave solar radiation from satellite images", Solar Energy, vol. 77, no. 2, pp. 159-169, 2004.

[29] M Girodo, R W Mueller and D. Heinemann, "Influence of three dimensional cloud eff ects on satellite derived solar irradiance estimation First approaches to improve 
the Heliosat method", Solar Energy, vol. 80, no. 9, pp. 1145 - 1159, 2006.

[30] L F Zarzalejo, L Ramirez, and J. Polo, "Artificial intelligence techniques applied to hourly global irradiance estimation from satellite-derived cloud index", Energy, vol. 30, no. 9, pp. 1685 - 1697, 2005.

[31] K F Dagestad and J. A. Olseth, "A modified algorithm for calculating the cloud index", Solar Energy, vol. 81, no. 2 , pp. $280-289,2007$.

[32] R Mueller, K Dagestad, P Ineichen, M SchroedterHomscheidt, S Cros, D Dumortier, R Kuhlemann, J Olseth, G Piernavieja, C Reise, L Wald, and D. Heinemann, "Rethinking satellite-based solar irradiance modelling: The SOLIS clear-sky module", Remote Sensing of Environment, vol. 91, no. 2, pp. $160-$ 174,2004 .

[33] R Perez, P Ineichen, K Moore, M Kmiecik, C Chain, R George and F. Vignola, "A new operational model for satellite-derived irradiances: description and validation", Solar Energy, vol. 73, no. 5, pp. 307 - 317,2002.

[34] P Ineichen, and R. Perez, “A new airmass independent formulation for the Linke turbidity coefficient", Solar Energy, vol. 73, no. 3, pp. 151-157, 2002.

[35] V. Badescu, "Modeling Solar Radiation at the Earth Surface”, Berlin Heidelberg: Springer-Verlag, 2008.

[36] R Perez, P Ineichen, M Kmiecik, K Moore, D Renne and R. George, "Producing satellite-derived irradiances in complex arid terrain", Solar Energy, vol. 77, no. 4, pp. $367-371,2004$.

[37] C.W., Chow, B Urquhart, M Lave, A Dominguez, J Kleissl, J Shields and B. Washom., "Intra-hour forecasting with a total sky imager at the UC San Diego solar energy testbed", Solar Energy, vol. 85, no. 11, pp. 2881-2893,Nov. (2011),

[38] Y. E. Systems, “TSI-880 Automatic Total Sky Imager", Airport Industrial Park 101 Industrial Blvd. Turners Falls, MA 01376 USA. (2012)

[39] Y. Chu, H T C Pedro, L Nonnenmacher, R H Inman, Z Liao and C.F.M. Coimbra., "A smart image-based cloud detection system for intra hour solar irradiance forecasts", J. Atmos. Oceanic Technol., vol. 31, no.9, pp.1995 - 2007, Sep. (2014),

[40] R. Marquez, H T C Pedro and C. F. M. Coimbra, "Hybrid solar forecasting method uses satellite imaging and ground telemetry as inputs to ANNs", Solar Energy, vol. 92, pp. 176-188, Jun..,(2013),

[41] S Quesada-Ruiz, Y Chu, J Tovar-Pescador, H T C Pedro and C.F.M. Coimbra., "Cloud tracking methodology for intra-hour \{DNI\} forecasting", Solar Energy, vol.102, pp.267 - 275, Apr. (2014),

[42] D Bernecker., C Riess, E Angelopoulou and J. Hornegger., "Continuous short-term irradiance forecasts using sky images", Solar Energy, vol. 110, pp.303 315, Dec. (2014),

[43] S. R. West Rowe, .D Sayeef .S., and A. Berry., "Shortterm irradiance forecasting using skycams: Motivation and development", Solar Energy, vol. 110, pp.188 - 207, Dec, 2014
[44] Y Chu, H T C Pedro and C.F.M. Coimbra., "Hybrid intra-hour DNI forecasts with sky image processing enhanced by stochastic learning", Solar Energy, vol. 98, part C, pp.592-603, Dec. (2013),

[45] H Yang, B Kurtz, D Nguyen, B Urquhart, C W Chow, M Ghonima and J. Kleissl., "Solar irradiance forecasting using a ground-based sky imager developed at UC San Diego", Solar Energy, vol.103, pp.502 - 524, May. (2014),

[46] R Li, B Zeng, and M. L. Liou., "A new three-step search algorithm for block motion estimation", IEEE Trans. on Circuits and Systems for Video Technology, vol. 4, no.4, pp. 438-442, Aug. (1994),

[47] M Sayed., "A fast architecture for exhaustive search block matching algorithm with MPEG4 applications", 16th IEEE Int. Conf. on Electronics, Circuits, and Systems, Yasmine Hammamet, pp.787-790, Dec. (2009),

[48] Q X Wu , “A correlation-relaxation-labeling framework for computing optical flow-template matching from a new perspective", IEEE Trans. Pattern Anal. Mach. Intell., vol. 17, no.9, pp.843 - 853, Sep.

[49] J R Stroud, M L Stein, B M Lesht, D J Schwab, and D. Beletsky., "An ensemble Kalman filter and smoother for satellite data assimilation", J. of the American Statistical Association, vol. 105, no.491, pp.978-990. (2010),

[50] Y Chu, B Urquhart, S M I Gohari, H T C Pedro, J Kleissl and C.F.M. Coimbra., "Short-term reforecasting of power output from a 48 MWe solar PV plant", Solar Energy, vol. 112, pp. 68 - 77, Feb, 2015.

[51] C L Fu and H.-Y. Cheng., "Predicting solar irradiance with all-sky image features via regression", Solar Energy, vol. 97, pp.537 - 550, Nov, 2013.

[52] A Kazantzidis, P Tzoumanikas, A F Bais, S Fotopoulos and G. Economou., "Cloud detection and classification with the use of wholesky ground-based images", Atmospheric Research, vol. 113, pp.80 - 88, Sep, 2012.

[53] S Cros, O Liandrat, N Sebastien and N. Schmutz., "Extracting cloud motion vectors from satellite images for solar power forecasting", IEEE Int. Geoscience and Remote Sensing Symp., Quebec City, pp. 4123 - 4126, 2014.

[54] A Hammer, D Heinemann, E Lorenz and B. Lückehe., "Short term forecasting of solar radiation: a statistical approach using satellite data", Solar Energy, vol. 67, no. 1-3, pp.139 - 150, Jul,1999.

[55] R Perez, P Ineichen, K Moore, M Kmiecik, C Chain , R George and F. Vignola., "A new operational model for satellite-derived irradiances: description and validation" Solar Energy, vol. 73, no. 5, pp.307 - 317, Nov, 2002.

[56] R Perez, P Ineichen, M Kmiecik, K Moore, D Renne and R. George., "Producing satellite-derived irradiances in complex arid terrain”, Solar Energy, vol. 77, no.4, pp.367 -371 , Oct, 2004

[57] R. Marquez and C. F. M. Coimbra, "Intra-Hour DNI Forecasting Methodology Based on Cloud Tracking Image Analysis," submitted to Solar Energy, 2012.

[58] M. Lave, J. Kleissl, and E. Arias-Castro, "Highfrequency irradiance fluctuations and geographic smoothing," Solar Energy, pp. 1-17, 2011. 
[59] A. Kamthe, R. Marquez, C. F. M. Coimbra, and A. Cerpa, "Sub-Minute Solar Irradiance Forecasting Using Wireless Sensor Networks." University of California, Merced, 2011.

[60] V Bjerknes, E Volken, and S. Bronnimann., The problem of weather prediction, considered from the viewpoints of mechanics and physics, Meteorologische Zeitschrift, vol. 18, no. 6, pp. 663-667,Dec, 2009.

[61] E Lorenz, J Hurka, D Heinemann and H G Beyer., Irradiance forecasting for the power prediction of grid connected photovoltaic systems", IEEE J. of Selected Topics in Applied Earth Observations and Remote Sensing, vol.2, no.1, pp.2-10, Apr, 2009.

[62] P Mathiesen, C Collier, and J. Kleissl., "A highresolution, cloud assimilating numerical weather prediction model for solar irradiance forecasting", Solar Energy, vol.92, no.0, pp.47-61, 2013.

[63] R Perez, E Lorenz, S Pelland, M Beauharnois, G V Knowe, K H Jr, D Heinemann, J Remund, S C Muller, W Traunmuller, G Steinmauer, D Pozo, J A Ruiz-Arias, V Lara-Fanego, L Ramirez-Santigosa, M GastonRomero, and L. M. Pomares., "Comparison of numerical weather prediction solar irradiance forecasts in the US, Canada and Europe", Solar Energy, vol.94, no.0, pp.305-326, Aug, 2013.

[64] H M Diagne, M David, J Boland, N Schmutz and P. Lauret., "Post-processing of solar irradiance forecasts from WRF model at Reunion Island", Solar Energy, vol.105, no.0, pp.99 - 108, Jul, 2014.

[65] P Mathiesen and J. Kleissl., "Evaluation of numerical weather prediction for intraday solar forecasting in the continental united states", Solar Energy, vol.85, no.5, pp.967 - 977, May, 2011.

[66] J Kleissl, "Solar Energy Forecasting and Resource Assessment", Academic Press, 2013.

[67] E Lorenz, D Heinemann, H Wickramarathne, H G Beyer and S. Bofinger., "Forecast of ensemble power production by grid-connected PV systems", Proc. 20th European PV Conf., Milano, Italy, Sep, 2007.

[68] E Lorenz, J Hurka, D Heinemann and H G Beyer., "Irradiance forecasting for the power prediction of grid connected photovoltaic systems", IEEE J. of Selected Topics in Applied Earth Observations and Remote Sensing, vol.2, no.1, pp.2-10, Apr, 2009.

[69] D Heinemann, E Lorenz, and M. Girodo., "Forecasting of solar radiation. In Solar Energy Resource Management for Electricity Generation from Local Level to Global Scale", E.D. Dunlop, L. Wald, and M. Šúri (Eds.), Nova Science Publishers, Hauppauge, NY, pp.83-94, 2006.

[70] R Perez, K Moore, S Wilcox, D Renné and A. Zelenka., "Forecasting solar radiation-preliminary evaluation of an approach based upon the national forecast database", Solar Energy, vol. 81, no. 6, pp. 809- 812, June, 2007.

[71] J Remund, R Perez, and E. Lorenz., "Comparison of solar radiation forecasts for the USA", Proc. 23rd European Photovoltaic Solar Energy Conference, Valencia, Spain, pp. 1.9-4.9, 2008.

[72] R Perez, S Kivalov, J Schlemmer, K H Jr, D Renne' and T.E. Hoff., "Validation of short and medium term operational solar radiation forecasts in the US", Solar Energy, vol. 84, no. 12, pp. 2161-2172, Dec, 2010.

[73] S Bofinger and G. Heilscher., "Solar Electricity Forecast - Approaches and first results", Proc. 21st European Photovoltaic Solar Energy Conf., Dresden, Germany, 2006.

[74] F Yang, H L Pan, and S. K. Krueger., "Evaluation of the NCEP Global Forecast System at the ARM SGP Site", Monthly Weather Review, vol. 134, pp. 3668-3690, 2006.

[75] F Yang, K Mitchell, Y T Hou, Y Dai, X Zeng, Z Wang and X.-Z. Liang, "Dependence of Land Surface Albedo on Solar Zenith Angle: Observations and Model Parameterization", Journal of Applied Meteorology and Climatology, vol. 47, no. 11, pp. 2963-2982, 2008.

[76] E Lorenz, T Scheidsteger, J Hurka, D Heinemann and C Kurz, "Regional PV power prediction for improved grid integration", Progress in Photovoltaics: Research and Applications, vol.19, no.7, pp.757-771, 2011.

[77] E Lorenz, D Heinemann, and C. Kurz., "Local and regional photovoltaic power prediction for large scale grid integration: assessment of a new algorithm for snow detection", Progress in Photovoltaics: Research and Applications, vol.20, no.6, pp. 760-769, 2011.

[78] S G Benjamin, W R Moninger .W, S S Weygandt, M Hu, D Devenyi, J M Brown, T Smirnova, J Olson, C Alexander, K Brundage, G Grell, S Peckham, T L Smith, S R Sahm and B. Jamison., "Technical Review of Rapid Refresh/RUC Project", tech. rep., NOAA/ESRL/GSD internal review, Nov, 2009.

[79] A. Wold, "Analysis of stationary time series", Uppsala: Almquist and Wicksell, 1938.

[80] M Sulaiman, W Hlaing, M Wahab and Z. Sulaiman, "Analysis of residuals in daily solar radiation time series", Renewable Energy, vol. 11, pp. 97-105, May 1997.

[81] G E P Box and G M Jenkins, "Time series analysis, forecasting and control”, Wiley, 1998.

[82] L. Ljung, "System Identification: Theory for the User", Prentice-Hall, 1987.

[83] T N Goh and K J Tan, "Stochastic modeling and forecasting of solar radiation data", Solar Energy, vol. 19, no. 6, pp. 755-757, 1977.

[84] J A K Suykens, J P L Vandewalle and B. L. R. Moor., "Artificial neural networks for modelling and control of non-linear systems", The Netherlands: Kluwer Academic, 1996.

[85] S M Al-Alawi and H.A. Al-Hinai., "An ANN-based approach for predicting global radiation in locations with no direct measurement instrumentation", Renewable Energy, vol. 14, no. 1-4, pp.199 - 204, May-Aug, 1998.

[86] G Capizzi, C Napoli, and F. Bonanno., "Innovative second generation wavelets construction with recurrent neural networks for solar radiation forecasting", IEEE Trans. on Neural Networks and Learning Systems, vol.23, no.11, pp.1805-1815, Nov, 2012.

[87] S K Chow, E W Lee and D.H. Li., "Short term prediction of photovoltaic energy generation by 
intelligent approach", Energy and Buildings, vol.55, pp.660-667, 2012.

[88] A Sozen, E Arcaklioglu, M Ozalp and N. Caglar., "Forecasting based on neural network approach of solar potential in Turkey", Renewable Energy, vol.30, no.7, pp.1075 - 1090, 2005.

[89] J. Wu, and K.C. Chee., "Prediction of hourly solar radiation using a novel hybrid model of ARMA and TDNN", Solar Energy, vol.85, no.5, pp.808 - 817, 2011.

[90] J Cao, and X. Lin., "Study of hourly and daily solar irradiation forecast using diagonal recurrent wavelet neural networks", Energy Conversion and Management, vol.49, no.6, pp.1396 - 1406, 2008.

[91] F Almonacid, P Pérez-Higueras, E F Fernández, and L. Hontoria., "A methodology based on dynamic artificial neural network for short-term forecasting of the power output of a PV generator", Energy Conversion and Management, vol.85, pp.389-398, 2014.

[92] C S Ioakimidis, S Lopez, K N Genikomsakis, P Rycerski and D. Simic., "Solar production forecasting based on irradiance forecasting using artificial neural networks", 39th Annu. Conf. of Industrial Electronics Society (IECON), Vienna, pp. 8121-8126, Nov, 2013.

[93] R.M Ehsan., S P Simon and P.R. Venkateswaran., "Dayahead prediction of solar power output for gridconnected solar photovoltaic installations using Artificial Neural Networks", IEEE 2nd Int. Conf. on Emerging Electronics (ICEE), Bangalore, pp.1-4, Dec,2014.

[94] A Yona , T Senjyu, A Saber, T Funabashi, H Sekine, and C H. Kim., "Application of neural network to 24hour-ahead generating power forecasting for PV system", IEEE Proc. in Power and Energy Society General Meeting - Conversion and Delivery of Electrical Energy in the 21st Century, pp.1-6, Jul, 2008.

[95] Y K Wu, C R Chen and H. Abdul-Rahman., “A novel hybrid model for short-term forecasting in PV power generation", Int. J. of Photoenergy, vol.2014, pp.1-9, 2014.

[96] F O G Hocaoglu, N Omer and M. Kurba., "Hourly solar radiation forecasting using optimal coefficient 2-D linear filters and feedforward neural networks", Solar Energy, vol.82, pp. 714-726, 2008.

[97] A Azadeh, A Maghsoudi, and S. Sohrabkhani., "An integrated artificial neural networks approach for predicting global radiation", Energy Conversion and Management, vol.50, no.6, pp. 1497 - 1505, 2009.

[98] A Mellit and A M Pavan., "A 24-h forecast of solar irradiance using artificial neural network: Application for performance prediction of a gridconnected PV plant at Trieste, Italy", Solar Energy, vol. 84, no.5, pp.807 - 821, 2010 .

[99] W K Yap and V. Karri., "Comparative study in predicting the global solar radiation for Darwin", Australia, J. of Solar Energy Engineering, vol. 134, no.3.,2012.

[100] R Guarnieri, F Martins, E Oereira and S. Chuo., "Solar radiation forecasting using artificial neural networks", National Institute for Space Research, vol.1, pp. 1-34, 2008.
[101] Y Kemmoku, S Orita, S Nakagawa and T. Sakakibara., "Daily insolation forecasting using a multistage neural network", Solar Energy, vol. 66, no.3 ,pp. 193-199, 1999

[102] G Mihalakakou, M Santamouris and D N Asimakopoulos., "The total solar radiation time series simulation in Athens, using neural networks", Theoretical and Applied Climatology, vol.66, pp. 185197, 2000.

[103] S fetsos, and A.H. Coonick., "Univariate and Multivariate forecasting of hourly solar radiation with artificial intelligence techniques", Solar Energy, vol.68, pp. 169-178, 2000

[104] S Cao , and J Cao., "Forecast of solar irradiance using recurrent neural networks combined with wavelet analysis", Applied Thermal Engineering, vol.25, no.2-3 pp. 161 - 172, 2005.

[105] J Cao , and S Cao., "Study of forecasting solar irradiance using neural networks with preprocessing sample data by wavelet analysis", Energy, vol.31, no.15, pp.3435 - 3445, 2006.

[106] P Mandal, S T S Madhira, A U Haque, J Meng and R. L. Pineda., "Forecasting power output of solar photovoltaic system using wavelet transform and artificial intelligence techniques", Proc. Computer Science, vol. 12, pp. 332 - 337, 2012.

[107] A Mellit, M Benghanem and S.A. Kalogirou., "An adaptive wavelet-network model for forecasting daily total solar radiation", Applied Energy, vol.83, pp. 705$722,2006$.

[108] C Shuanghua, W Wenbing, C Jianbo, L Weidong, Y Guoging and C. Jiacong, "Forecast of Solar Irradiance using chaos optimization neural networks", Asia-Pacific Power and Energy Engineering Conf. (APPEEC), Wuhan, pp.1-4, Mar, 2009.

[109] D K Chaturvedi , "Forecasting of Solar Power using Quantum GAGNN", Int. J. of Computer Applications, vol. 128, no. 3, pp. 15-19,2015.

[110] W Jianping, $\mathrm{X}$ Yunlin, $\mathrm{Z}$ Chenghui and $\mathrm{X}$. Xiaobing., "Daily solar radiation prediction based on Genetic Algorithm Optimization of Wavelet Neural Network", Int. Conf. on Electrical and Control Engineering (ICECE), Yichang, pp.602-605, Sep, 2011.

[111] Y Zhengque, C Yapei, and X. Jiapeng., "Power generation forecasting model for photovoltaic array based on generic algorithm and BP neural network", IEEE 3rd Int. Conf. on Cloud Computing and Intelligence Systems (CCIS), Shenzhen, pp.380-383, Nov, 2014.

[112] S Hussain and A. Al Alili., "Soft Computing approach for solar radiation prediction over Abu Dhabi, UAE: A comparative analysis", IEEE Conf. on Smart Energy Grid Engineering (SEGE), Oshawa, ON, pp.1-6, Aug, 2015.

[113] M Farhadi and M. Farshad., "A fuzzy inference selforganizing-map based model for short term load forecasting", Proc. of 17th Conf. on Electrical Power Distribution Network (EPDC), Tehran, pp.1-9, May, 2012. 
[114] A Yona, T Senjyu, T Funabashi and C.-H. Kim., "Neural Network for Long-Term Ahead PV Power Output Correction", IEEE Trans. on Sustainable Energy, vol.4, no.2, pp.527-533, Apr, 2013.

[115] V P Singh, V Vijay, M S Bhatt and D K Chaturvedi., "Generalized neural network methodology for short term solar power forecasting", 13th Int. Conf. on Environmental and Electrical Engineering (EEEIC), Wroclaw, pp.58-62, Nov, 2013.

[116] L A Fernandez-Jimenez, A Muoz-Jimenez, M Mendoza-Villena, A Falces, E Garcia-Garrido, P M LaraSantillan, E Zorzano-Alba, and P J Zorzano Santamaria., "Short-term power forecasting system for photovoltaic plants, Renewable Energy", vol. 44, no. 0, pp. 311 - 317, 2012 .

[117] E Grimaccia, M Mussetta and R. Zich., "Neurofuzzy predictive model for PV energy production based on weather forecast", IEEE Int. Conf. on Fuzzy Systems (FUZZ), Taipei, pp.2454-2457, Jun, 2011.

[118] R Xu, H Chen, and X. Sun., "Short-term photovoltaic power forecasting with weighted support vector machine", IEEE Int. Conf. on Automation and Logistics (ICAL), pp. 248-253,2012.

[119] J Shi, W J Lee, Y Liu, Y Yang, and P Wang, "Forecasting power output of photo voltaic systems based on weather classification and support vector machines", IEEE Trans. on Industry Applications, vol. 48, no. 3, pp. 1064 -1069, May-Jun, 2012.

[120] A U Haque, M H Nehrir, and P. Mandal., "Solar PV power generation forecast using a hybrid intelligent approach", IEEE Conf. on Power and Energy Society General Meeting (PES), Vancouver, BC, pp.1-5, Jul, 2013.

[121] Y Hong-Tzer, H Chao-Ming, H Yann-Chang and P. Yi-Shiang, "A Weather-Based Hybrid Method for 1-Day Ahead Hourly Forecasting of PV Power Output", IEEE Trans. on Sustainable Energy, vol.5, no.3, pp.917926, Jul,2014.

[122] A Mellit, A Hadjarab, N Khorissi and H Salhi., "An ANFIS based Forecasting for solar radiation data from sunshine duration and ambient temperature", IEEE Power Engineering Society General Meeting, Tampa, FL, pp.1-6, Jun 2007.

[123] Y Cheng, $X$ Jiapeng, L Chen and Y Zhengqiu., "A high concentrated photovoltaic output power predictive model based on Fuzzy Clustering and RBF neural network", IEEE 3rd Int. Conf. on Cloud Computing and Intelligence Systems (CCIS), Shenzhen, pp.384-388, Nov,2014.

[124] M Cococcioni, E D'Andrea and B. Lazzerini., "24hour-ahead forecasting of energy production in solar PV systems", 11th Int. Conf. on Intelligent Systems Design and Application (ISDA), Cordoba, pp.1276-1281, Nov, 2011

[125] G Reikard, "Predicting solar radiation at high resolutions: A comparison of time series forecasts", Solar Energy, vol.83, no.3, pp.342 - 349, Mar, 2009.

[126] C Voyant, M Muselli, C Paoli, and M.-L. Nivet., "Optimization of an artificial neural network dedicated to the multivariate forecasting of daily global radiation", Energy, vol. 36, vol. 1, pp. 348 - 359, Jan, 2011

[127] C Chen, S Duan .,T. Cai , and B. Liu., "Online 24$\mathrm{h}$ solar power forecasting based on weather type classification using artificial neural network", Solar Energy, vol. 85, no. 11,pp. 2856 - 2870, 2011

[128] Pedro .H. T. and C.F.M. Coimbra., "Assessment of forecasting techniques for solar power production with no exogenous inputs", Solar Energy, vol.86, no.7, pp. $2017-2028,2012$.

[129] R. Marquez, H T C Pedro and C. F. M. Coimbra. "Hybrid solar forecasting method uses satellite imaging and ground telemetry as inputs to ANNs", Solar Energy, vol. 92, pp. 176-188, Jun, 2013.

[130] Z. Dong, D Yang, T Reindl and W.M. Walsh., "Satellite image analysis and a hybrid ESSS/ANN model to forecast solar irradiance in the tropics", Energy Conversion and Management, vol.79, pp.66 - 73, 2014

[131] C Cornaro, M Pierro, F Bucci., "Master optimization process based on neural networks ensemble for 24-h solar irradiance forecast", Solar Energy, vol.111, pp. $297-312,2015$.

[132] J Zhang, B M Hodge, A Florita, S Lu, H F Hamann and V. Banunarayanan., "Metrics for Evaluating the Accuracy of Solar Power Forecasting", 3rd Int. Workshop on Integration of Solar Power into Power Systems, London, Oct, 2013.

[133] B Espinar, L Ramirez, A Drews, H G Bayer, L F Zarzalejo, J Polo and L. Martin., "Analysis of different comparison parameters applied to solar radiation data from satellite and German radiometric stations", Solar Energy, vol.83, no.1, pp.118-125, 2009.

[134] B M Hodge, $\mathrm{K}$ Orwig, and M Milligan. "Examining Information Entropy Approaches as Wind Power Forecasting Performance Metrics", 12th Int. Conf. on Probabilistic Methods Applied to Power Systems, Istanbul, Turkey, pp.1-6, June, 2012.

[135] R.J Bessa, V Miranda, A Botterud and J. Wang., “ 'Good' or 'bad' wind power forecasts: A relative concept", Int. J. on Wind Energy, vol.14, no.5, pp.625636, July, 2011.

[136] A Mills, and R Wiser., "Implications of Wide-Area Geographic Diversity for Short-Term Variability of Solar Power, Report on Environmental Energy Technologies Division", Ernest Orlando Lawrence Berkeley National Laboratory, 2010.

[137] K Orwig, B M Hodge, G Brinkman, E Ela, and M. Milligan., "Economic Evaluation of Short-Term Wind Power Forecasts in ERCOT: Preliminary Results", 11th Annu. Int. Workshop on Large-Scale Integration of Wind Power into Power Systems as well as on Transmission Networks for Offshore Wind Power Plants Conference, Lisbon, Portugal, Nov. 2012.

[138] F O Hacaoglu, O N Gerek , and M. Kurban., "Hourly solar radiation forecasting using optimal coefficient 2-d linear filters and feed-forward neural networks", Solar Energy, vol.82, no.8, pp.714-726.,2008. 
[139] Bacher, H Madsen and H A Nielsen., "Online short-term solar power forecasting", Solar Energy, vol.83, no.10, pp.1772 - 1783, 2009.

[140] L Martin, L F Zarzalejo, J Polo, A Navarro, R Marchante, and M. Cony., 'Prediction of global solar irradiance based on time series analysis: Application to solar thermal power plants energy production planning", Solar Energy, vol. 84, no. 10, pp.1772-1781, 2010.

[141] A Mellit, H Eleuch, M Benghanem, C Elaoun and A M Pavan., "An adaptive model for predicting of global, direct and diffuse hourly solar irradiance", Energy Conversion and Management, vol. 51, no. 4, pp.771-782, 2010 .

[142] C Paoli , C Voyant, M Muselli, and M. -L. Nivet., "Forecasting of pre-processed daily solar radiation time series using neural networks", Solar Energy, vol. 84, no. 12, pp. 2146-2160, 2010.

[143] R Marquez and C F M Coimbra. "Forecasting of global and direct solar irradiance using stochastic learning methods, ground experiments and the NWS database", Solar Energy, vol.85, no. 5, pp.746-56, 2011.

[144] C Voyant, M Muselli, C Paoli and M. -L. Nivet., "Numerical Weather Prediction (NWP) and hybrid ARMA/ANN model to predict global radiation", Energy, vol.39, no.1, pp.341-355,2012.

[145] R Marquez, V Gueorguiev, and C F M Coimbra., "Forecasting of global horizontal irradiance using sky cover indices", ASME J. of Solar Energy Engineering, vol. 135, no.1, pp.61-69,2013.

[146] R Marquez and C F M Coimbra., "Intra-hour DNI forecasting based on cloud tracking image analysis", Solar Energy, vol. 91, pp.327 - 336, 2013.

[147] J L Bosch, Y Zheng and J. Kleissl., "Deriving cloud velocity from an array of solar radiation measurements", Solar Energy, vol.87, pp.196-203,2013.
[148] C Voyant, P Randimbivololona, M L Nivet, C Paoli and M. Muselli, "Twenty four hours ahead global irradiation forecasting using multi-layer perceptron", Meteorological Applications, vol. 21, no. 3, pp.644655,2014

[149] SHaykin"Neural Networks and Learning Machines”, Prentice Hall, 2008.

[150] B. Amrouche, and X.L. Pivert., "Artificial Neural Network based daily local forecasting for global solar radiation", Applied Energy, vol.130, pp.333-341,2014.

[151] M Ghayekhloo , M Ghofrani, M B Menhaj, and R. Azimi., "A novel clustering approach for short-term solar radiation forecasting", Solar Energy, vol.122, pp.13711383,2015

[152] E Akarslan and F O Hacaoglu., "A novel adaptive approach for hourly solar radiation forecasting", Renewable Energy, vol.87, pp. 628-633, 2016.

[153] Y Gala, A Fernandez, J Diaz , and J R Dorronsoro., "Hybrid machine learning forecasting of solar radiation values", Neurocomputing, vol.176, pp. 48-59, 2016.

[154] V Sharma, D Yang, W Walsh ., T Reindl., "Short term solar irradiance forecasting using a mixed wavelet neural network", Renewable Energy, vol. 90, pp.481492, 2016

[155] R H Inman, H T C Pedro and C.F.M.Coimbra., "Solar forecasting methods for renewable energy integration", Progress in Energy and Combustion Science, vol.39, pp.535-576, 2013

[156] A Kamtha, R Marquez, C F M Coimbra and A Cerpa, "Sub-minute solar irradiation forecasting using wireless sensor network", 2011. 